\title{
Coordinating Reforms in Transition Economies ${ }^{1}$
}

\author{
Yingyi Qian \\ Department of Economics \\ University of California, Berkeley \\ and CEPR \\ Gérard Roland \\ University of California, Berkeley \\ and CEPR \\ and \\ Chenggang Xu \\ Department of Economics \\ London School of Economics \\ and CEPR
}

November, 1999

\begin{abstract}
$\underline{\text { Abstract }}$
We establish a theory to analyze how initial conditions of organizational differences in transition economies affect reform strategies, especially the "big-bang" approach in Eastern Europe and former Soviet Union economies as the U-form and the "experimental" approach in China as the M-form. We model the coordination of specialized tasks inside an organization as "attribute matching" and compare organizational forms (U-form and M-form) in coordinating reforms. Organizational forms affect the information structure of an organization and thus the way to coordinate reforms. Compared to the Uform, the M-form organization achieves better coordination but suffers from higher costs due to a lack of scale economies. The $\mathrm{M}$-form has a distinctive advantage in carrying out experimentation that it is more flexible in reforms.
\end{abstract}

\footnotetext{
${ }^{1}$ We are grateful to Wei Li, Paul Milgrom, Dani Rodrik, Oliver Williamson, and the participants at the Fifth Nobel Symposium in Economics for helpful discussions and comments. Roland and Xu benefitted from an ACE grant and Roland benefitted from a fellowship at the Center for Advanced Studies in Behavioral Sciences at Stanford in 1998-99.
} 


\section{Introduction}

Gradual and experimental are often characterized as a major feature of The Chinese reform to differentiate those in formal Soviet Union (FSU) and Central Eastern Europe (CEE). This popular argument claims that China has followed an experimental approach whereas Eastern Europe and the former USSR followed the "big bang" strategy after 1989. China's reforms first started in experiments in agriculture and then moved into experiments in special economic zones in cities. ${ }^{2}$ However, some experimental reforms were introduced in the Soviet Union in the 1980s but failed. It is on this basis, the experimental approach to reforming a planned economy has been discredited and abandoned during the later transition. The Eastern European radical transition came after deep troubles or failures of many years of gradual reforms with experimental approaches. Ironically, to a large extent, China followed many of the Eastern European gradual reform measures including experiments in earlier stages of its reforms. In fact, the Hungarian reform started in 1968 with some initial success, but then ran into difficulties in the 1980s. A very important, but tends to be neglected fact associated with the failures of the CEE-FSU earlier reforms, is their economic stagnation for the decade of 1980s before the radical changes since 1990. According to official statistics, the average growth rate of GDP in Hungary was 1.8\% between 1981 and 1985 and almost zero in 1988 and 1989. In Poland, the average GDP growth rate was less than $2 \%$ between 1981 and $1989 .{ }^{3}$ Reform should not be based on experiments is a conclusion or a lesson drawn by many economists from the failures of the experimental reforms in CEE-FSU economies. Therefore, a proper question to be raised is, why has experimental approach worked in China but not in Eastern Europe?

In this paper, we propose a theory, which opens new perspectives on understanding how the

2 For related literature, see Singh (1991), McMillan and Naughton (1992), Dewatripont and Roland (1997), Sachs and Woo, 1997.

3 Data source for Hungary and Poland is from Table 9.1 of Kornai (1992). 
differences in organizational forms of centralized economies in the Soviet Union and China affected their reforms and transition paths. It allows us to address the following question: what makes China succeed in applying experimental approaches whereas CEE-FSU economies failed in experimental approaches in reforms?

The central point of our theory is that different organizational forms differ in their coordination capacity. How do organizational forms of a centralized economy or organizational forms inside government affect economic reform strategies in transition economies? What is the difference between coordinating changes in a unitary (centralized) state with specialized ministries and in a federal state with coordinating powers delegated to regions? What is the difference between coordinating innovation in a business firm run by specialized departments and in a firm that is run by self-contained profit centers?

To answer these questions, we introduce the concept of task coordination inside an organization as matching the attributes of specialized tasks in a stochastic environment, which is inspired by Milgrom and Roberts (1992). We view coordination as reforming an economy by restructuring enterprises and establishing corresponding social safety-net; synchronizing travel plans and accommodating logistics for a conference, etc. Each complementary part is characterized by its attributes: time, location, technical specifications (such as size, weight, and bits), legal and administrative terms, etc. A reform program or a product is completed successfully only if the characteristics of each attribute of the various parts are matched.

In a world without uncertainty, as long as an organization has a perfect plan in which all the attributes are matched by design, all the tasks can be implemented without a problem. Alternatively, as long as all agents are able to communicate perfectly (no mistakes, no cost, no time) matching attributes will not be a problem either even when there is uncertainty. However, when there are exogenous random shocks which we will call "attribute shocks" and when communication between agents is imperfect, the coordination problem becomes non-trivial and having a perfect plan alone is insufficient. This is because 
when there is a shock affecting an attribute of one task, any change of this attribute will affect its matching with attributes of other tasks. Thus, the corresponding attributes of other tasks must be adjusted to make them match. But the quality of the adjustment of attributes depends itself on the quality of communication inside an organization. The communication problem arises because only a manager directly and frequently engaging in a particular task has first-hand information and knowledge about that task. Communication is necessary for others to use such information and knowledge, but communication is likely to be imperfect because message transmission, due to technical bugs as well as human misunderstanding, can go wrong. Hayek's (1945) famous notion of "local information," the information about particular location and circumstance, fits well our framework - direct involvement in a task gives rise to good knowledge about that task. The communication problems we consider are more general, they are not necessarily related to geographic distance. They arise whenever direct involvement is absent there is poor knowledge. For convenience, we often refer to a manager as "local manager" and the knowledge he possesses as "local information." Thus, the term "local" used here does not necessarily carry a geographical meaning.

However, the communication problem is endogenous, depending on how tasks and decisionmaking power are assigned within an organization, that is, the organizational form. We define an M-form (multi-divisional form) organization as one that consists of self-contained units where complementary tasks are grouped together. In contrast, a U-form (unitary form) organization is decomposed into specialized units where similar tasks are grouped together. These units are not self-contained in terms of final output. Because the M-form and the U-form organizations assign tasks differently, the communication problems they will face are different.

Our definition of $\mathrm{M}$-form and $\mathrm{U}$-form organizations helps us to characterize the striking difference between the organization of the Soviet planning administration and that of the Chinese planning administration (Qian and Xu, 1993). We may regard a centrally planned economy as a huge 
"firm" with the national government as the headquarters and ministries or subnational governments as sub-units of the firm. From this perspective, Eastern Europe and the former Soviet Union (EEFSU) economies were organized as a gigantic U-form (also known as a "branch organization"), where stateowned enterprises were organized into many specialized or functional ministries (e.g., mining, machinery, textile, etc.), each controlling gigantic factories. On top of that, there was a high degree of regional industrial concentration. ${ }^{4}$ This central planning structure makes central coordination essential: In the late 1970s the Gosplan, which supervised all specialized ministries, was responsible for 48,000 plan "positions" and 12 million products (Nove, 1983).

In contrast, the Chinese economy has been organized mainly on a geographical principle (provinces, prefectures, counties, townships and villages). This corresponds to an M-form organization (also known as a "regional organization"), where most state-owned enterprises were under the control of regional governments. At the same time, industries were much less regionally concentrated than the EEFSU and the average size of Chinese enterprises was much smaller too. Typically, the production of each region was relatively self-contained. With regional governments taking major responsibilities for coordination, the central government's role of coordination was greatly reduced compared to that in the EEFSU. The Chinese State Planning Commission was never responsible for more than 1,000 products (Qian and Xu, 1993), and the central statistical agency in China had total staff of only 280 (in 1981), compared to 41,000 in the Soviet Union (in 1987) (Huang, 1994). ${ }^{5}$

\footnotetext{
${ }^{4}$ In the Soviet Union, for example, a large number of consumer goods and producer goods (e.g. sewing machines, freezers, hydraulic turbines, and 87 percent of all the 5,885 products in machine building industry) had only a single producer located in one geographic area. In 1988, about two thirds of all the products had no more than three producers (IMF et al., 1991, Vol. II, pp.39-40).

${ }^{5}$ We further note that the different organizational forms between China and the EEFSU is not due to the different sizes of the corresponding economies. In fact, China's central statistical agency was even smaller than that in Hungary, which is about 100 times smaller than China in terms of population. A comparison between Hungary and a small Chinese province, Hainan, may further illustrate the point. Hungarian ministries controlled most of the firms before the transition. However, the control of firms in Hainan is distributed at different levels of hierarchy, although Hainan is smaller than Hungary, in terms of both population and GDP.
} 
The M-form structure provides flexibility and allows for regional experiments without interfering with the rest of the economy, and thus can optimally induce an experimental approach. The difficulties in coordination prevent the U-form from exploiting this strategy. In the latter, reforms must be more comprehensive in order to avoid coordination failure and must be coordinated from the top.

According to our theoretical analysis, the introduction of reforms (be they reforms within the central planning system or market-oriented reforms) in the EEFSU requires a comprehensive approach with coordination from the center. On the other hand, in China, reforms can proceed with local experiments, or even parallel experiments, because coordination is established locally. Indeed, plagued by many coordination problems, many previous reform experiments in the EEFSU were not successful. In contrast, China repeatedly adopted successfully an experimental approach to reforms.

In order to focus on the coordination problem, we assume away the incentive problem and take the team theoretical approach. Elsewhere, Maskin, Qian, and Xu (1999) provide an analysis of incentive problems in M-form and U-form organizations in a similar setup. They have demonstrated that different organizational forms give rise to different information about managers' performance and therefore differ according to how incentives encourage good performance. In particular, they have shown that the Mform may provide better incentives than the U-form because it promotes yardstick competition, that is, relative performance evaluation, more effectively. In this paper, we assume that managers under either organizational form have the same incentives to pursue the goal of economic efficiency. That is, there is no intrinsic advantage of one organizational form over another from the point of view of incentives. Therefore, all results are driven by coordination considerations.

In our theoretical model we made a symmetry assumption with two industries in each region. However, in reality, China and the Soviet Union had different patterns of industrial centralization on top of the organizational form. In China, because of regional industrial dispersion, the M-form (regionalbased) and the U-form (industrial-based) represented two different potential organizational forms and the Chinese adopted the former. In the Soviet Union, the initial U-form organization led to extreme industrial concentration where one region had only one industry. In that case, regions are not self-contained any 
more which means that the properties of the M-form cannot be obtained simply by devolution of powers to the regions. The initial choice of organizational form thus had an impact on location and size of industry. In the Soviet Union, these choices represented a "lock-in" of the U-form, making a change towards the M-form impossible without major indsutrial investment. This consideration also clarifies the confusion arising frequently in studying the Soviet Union and Russia. It is often thought that the devolution of authority to regional governments under Yeltsin in Russia after 1992 represents a shift from a U-form to an M-form. This is not true. In fact, such a change represents a shift from a U-form, as we have studied, to a "collapsed" U-form, which is equivalent to a U-form where the communication between local and central managers has completely broken down. This is because when industries are regionally concentrated and cannot be moved around easily, regions cannot be self-contained units as in the case of China.

We extend the analysis by introducing another dimension of the coordination problem, that of "attribute compatibility." Attribute compatibility is a characteristic related to similar tasks and products. Whereas attribute matching refers to complementary tasks such as manufacturing and sales of cars, compatibility refers to serving different types of cars. Cars have a better compatibility if different types share common services or parts. When coordination for attribute compatibility between similar tasks is also needed, the M-form may suffer from coordination problems due to imperfect communication between the local managers and the top manager, since in the M-form similar tasks are performed in different units. Then the comparison between the M-form and the U-form is focused on the tradeoff between two types of coordination: attribute compatibility and attribute matching. When standardization in markets is more prepared to solve most of the compatibility problems, the M-form will have more advantages than the U-form.

Our paper is, to our knowledge, the first to formalizing coordination as attribute matching. Milgrom and Roberts (1992) introduced the notion of design attributes to study the form of communication (prices or planned attributes) that should be used to coordinate a given decision. They find that non-price communication is optimal when errors of "fit" are very costly and the number of 
alternative possible designs that fit well is large. Unlike our study, Milgrom and Roberts focus only on the form of communication and do not consider the choice of alternative management structures to organize decisions when the need for attribute matching is pervasive.

Moreover, to our knowledge, our model is the first formal attempt at studying how the M-form and the U-form organizations affect communication channels and thus the efficiency of coordination within an organization. ${ }^{6}$ After the presentation of formal theory, we give applications to three areas: business firms, transition economies, and the organization of government.

Our theory is also relevant to the study of business firms. Becker and Murphy (1992) have emphasized that coordination costs limit the extent of specialization in organizations but do not compare the coordination capacity of various organizational forms. Chandler $(1962,1977)$ studied how the Mform corporation emerged and how it replaced the U-form to become the prevailing corporate form of large businesses in U.S. business history. Williamson $(1975,1985)$ theorized Chandler's works with two major focuses: the holdup problem and the overload problem of corporate headquarters. The holdup problem concerns how organizational forms affect incentives and contractual relationships within an organization. ${ }^{7}$ With respect to the coordination problem, Williamson emphasized that M-form firms were more efficient than U-form firms because daily operations were decentralized to divisions, which reduced

\footnotetext{
${ }^{6}$ The literature related to our work includes team theoretical studies of organization and management science literature. Team theory literature, among others, includes Marschak and Radner (1972) on the economic theory of teams, Weitzman (1974) on coordination using price and quantity, Crémer (1980) and Aoki (1986) on the optimal partition of workshops inside an organization, and Bolton and Dewatripont (1994) on the firm as a communication network. Related management science literature distinguishes between product-focused and process-focused corporations, and treats them as the result of minimization of coordination costs in varying unstable environments (Henderson and Clark, 1990, Hayes, Wheelwright, Clark, 1988, Stinchcombe, 1990, Athey and Schmutzler, 1994). Other related literature includes comparative studies of firms, for example, Aoki (1986) has noted that in Japanese firms, decision-making is more decentralized to workers who are less specialized and better able to make frequent adjustments and use on-site information than their American counterparts. These models, however, are not based on the notion of coordination as attribute matching.

${ }^{7}$ A large literature has been generated after Williamson, such as Grossman and Hart (1986) and Hart and Moore (1990).
} 
work overload at the corporate headquarters and freed their time for strategic planning. ${ }^{8}$ However, if overload is the only problem, putting more staff and resources in the headquarters and in functional departments should reduce the problem, and there is no need to undergo a reorganization process. Chandler $(1962,1977)$ documents that this is not the case. Our theory is consistent with Chandler's cases showing how the design of communication channels within an organization has fundamental effects on coordination.

Finally, our theory is useful in understanding the organization of government, specifically, the comparison between the unitary and federal state. The unitary state can be viewed as a U-form organization and federalism as an M-form. The organization of the French and Japanese governments are examples of the former and that of the United States is the prominent example of the latter. The French and Japanese government organizations are much more centralized in Paris and Tokyo respectively, with specialized ministries having large powers and regional governments having little. Major changes in government programs, such as education and banking reforms, require initialization by the responsible ministries and coordination by the central government. In contrast, American federalism is known as a "laboratory of the states," in the famous words of the American Supreme Court Justice Louis Brandeis written in 1932. Indeed, many government policy changes in the U.S. are experimented by some states and the successful results are imitated later by others. The contrast between the unitary and federal states fits well in our theoretical analysis of organizational forms.

The rest of the paper is organized as follows. Section II introduces basic concept of task coordination as "attribute matching" and sets up the model. Section III explores the basic features of the U-form and the M-form organizations in coordinating reforms. Section IV extends the model to include the possibility of parallel reform experiments when more than one blueprint is available at a given time. Section V incorporates coordination on attribute compatibility. Section VI applies our theory to explain

\footnotetext{
${ }^{8}$ Aghion and Tirole (1995) analyzed how M-form and U-form organizations generate and solve the overload problem.
} 
reform strategies in China and in former Soviet Union. Section VII discusses other applications of our theory in business and in political science. Section VII concludes. The Appendix contains the proofs of the propositions.

\section{Modelling Coordination as "Attribute Matching"}

The coordination concept in this paper relates to the adjustment of the organization to exogenous disturbances and random contingencies. This concept expresses the idea that a need for coordination arises in response to exogenous disturbances to pre-set plans. We look at taskcoordination decisions. There are usually many attributes of a set of tasks required to produce a product or to provide a service: time, location, technical specifications such as size, weight and bits, etc. A product or a service is completed only if characteristics of each attribute among a set of tasks are matched ("attribute fit," as referred to by Milgrom and Roberts, 1992). When there is a shock affecting an attribute in one task, the attribute in other tasks must be adjusted to achieve matching. There is a fundamental difference in the nature of these two basic adjustment decisions. Adjusting to attribute shocks means preserving the complementarity between tasks. Adjusting to attribute compatibility means organizing the substitution of resources among tasks so as to preserve optimal resource allocation.

Consider an economy with two regions (or products), "A" and "B," and two functions (or processes), "1" and "2." The technology of the economy can be fully described by four tasks: 1A, 2A, $1 \mathrm{~B}$, and $2 \mathrm{~B}$, where task ir involves process $\mathrm{i}$ for product $\mathrm{r}$. With this specification, we assume that the two products (or regions) are symmetric in the sense that each region has two functions.

We suppose that a reform program is designed so that all attributes are matched perfectly ex ante in the blueprints. However, in implementing a program, there are always "attribute shocks" which are unexpected contingencies not taken care of in the blueprints. At the implementation stage of a reform program, attributes of sub-programs must be mutually adjusted to observed attribute shocks. We assume 
that attribute matching must take place between tasks $1 \mathrm{r}$ and $2 \mathrm{r}(\mathrm{r}=\mathrm{A}, \mathrm{B})$. In sections III and IV, we assume that no attribute matching is needed between the tasks across regions and in section $\mathrm{V}$, we extend the model by incorporating the requirement for attribute compatibility across regions.

We consider an infinite horizon with discount factor $\delta$. We first assume that one and only one blueprint for change is available in each period to the top officer of the organization. Later we allow the possibility of two independent blueprints in each period. With probability $\mathrm{p}$ the blueprint is a good one and with probability 1-p it is bad. Blueprints available over time are stochastically independent. We assume that if a blueprint is known to be good, then it will be good in the same unit (region) in the future, or it can be good in another unit (region). In contrast, good coordination (i.e., attribute matching) in one unit (region) cannot be "copied" in another unit (region), because of differences in local conditions. Therefore, if a blueprint tried in one unit (region) is found to be good and coordination has been successful, then the same blueprint can be used successfully elsewhere, but coordination is still necessary in order to adjust to local conditions before a successful outcome can be achieved.

We assume that the officer of a unit has better "local" information about his unit than others. Thus, the effectiveness of corresponding adjustments will be determined by the quality of communication among the agents who are responsible for the related tasks. Moreover, we assume that communication within a unit is perfect, but cross-unit communication is imperfect. This is because when activities are shared by members of a unit they share local information and they communicate extensively with a common language (it can take many formats such as jargon, graphs, body language, etc.) which reduces misunderstandings. However, communication across groups is imperfect. This is because when agents are in separate specialized units, they have different idiosyncratic knowledge and different interpretations of the same message. They may speak different languages (e.g., engineering language differs from marketing language and the language of economists may differ from that of sociologists). Moreover, their communication may be restricted to short messages (such as messages carried by phone calls, faxes, memos, meetings, etc.), which may be subject to ambiguous interpretations.

A superior is specialized in supervising subordinate units and communicates with the units more 
often. However, units are not specialized in communicating with each other. We assume that the center receives imperfect information about shocks in all units but there is no horizontal communication between units. In this sense, a superior has better "global" information about all units than his subordinates do.

We model these differences in information in reduced form by assuming that in each period, if needed, a officer collects information about the attribute shocks and, if required, sends a message to another officer. Each message contains information about all the attributes in one task. We assume that the probability of each message being correct is $\lambda$ with $0 \leq \lambda \leq 1$. We assume that noises in information transmission are independent across tasks as well as over time. Based on the information received, the officer carries out his main job: attribute matching.

Consider the payoffs for unit A (payoffs for unit B are defined symmetrically). Let the status quo (without change) payoff in tasks $1 \mathrm{~A}$ and $2 \mathrm{~A}$ be $1 / 2$. The benefits from change are defined as follows. Suppose the program is good, then (i) with change in task 1A but not in task $2 \mathrm{~A}$ (or change in task $2 \mathrm{~A}$ but not in task $1 \mathrm{~A})$, the payoff is $(\mathrm{R}+1) / 4$ if the attributes between $1 \mathrm{~A}$ and $2 \mathrm{~A}$ are matched, otherwise 0 ; and (ii) with changes in both tasks $1 \mathrm{~A}$ and $2 \mathrm{~A}$, the payoff is $\mathrm{R} / 2$ if the attributes between $1 \mathrm{~A}$ and $2 \mathrm{~A}$ are matched, otherwise 0 . If the program is bad, then the payoff is always 0 when change is implemented.

Assumption 1. $\mathrm{pR}>1$ : the expected per-period benefit from change is larger than the status quo.

We assume that all blueprints are made available for free, but for each officer there is a setup cost $\mathrm{C}$ associated with coordinating changes. This cost can be interpreted as a training cost, that is, to implement a program for change the officers need to be trained on how to match attributes of the program. Because blueprints are free and the setup costs for coordination are not, when a failure occurs in the previous period (either due to a bad program or bad coordination), the organization always prefers to use a new blueprint in the next period rather than retry the old one.

Assumption 2. $\mathrm{R} / 2(1-\delta)-\mathrm{C}>1 / 2(1-\delta)$, that is, the net benefit from change is better than the status quo 
for $\mathrm{p}=1$.

We can now define U-form and M-form organizations. A U-form organization is set up along "functional lines." Two middle officers $i(i=1,2)$ are responsible for collecting information about shocks in tasks $\mathrm{iA}$ and $\mathrm{iB}$. Because the two tasks that need attribute matching are not assigned to the same middle officer, the two middle officers have to report the information to the top officer, who, after receiving information from the two officers, matches attributes between tasks $1 \mathrm{r}$ and $2 \mathrm{r}(\mathrm{r}=\mathrm{A}, \mathrm{B})$. This type of organization can be represented by Figure 1:

\section{Figure 1. An U-form Organization}

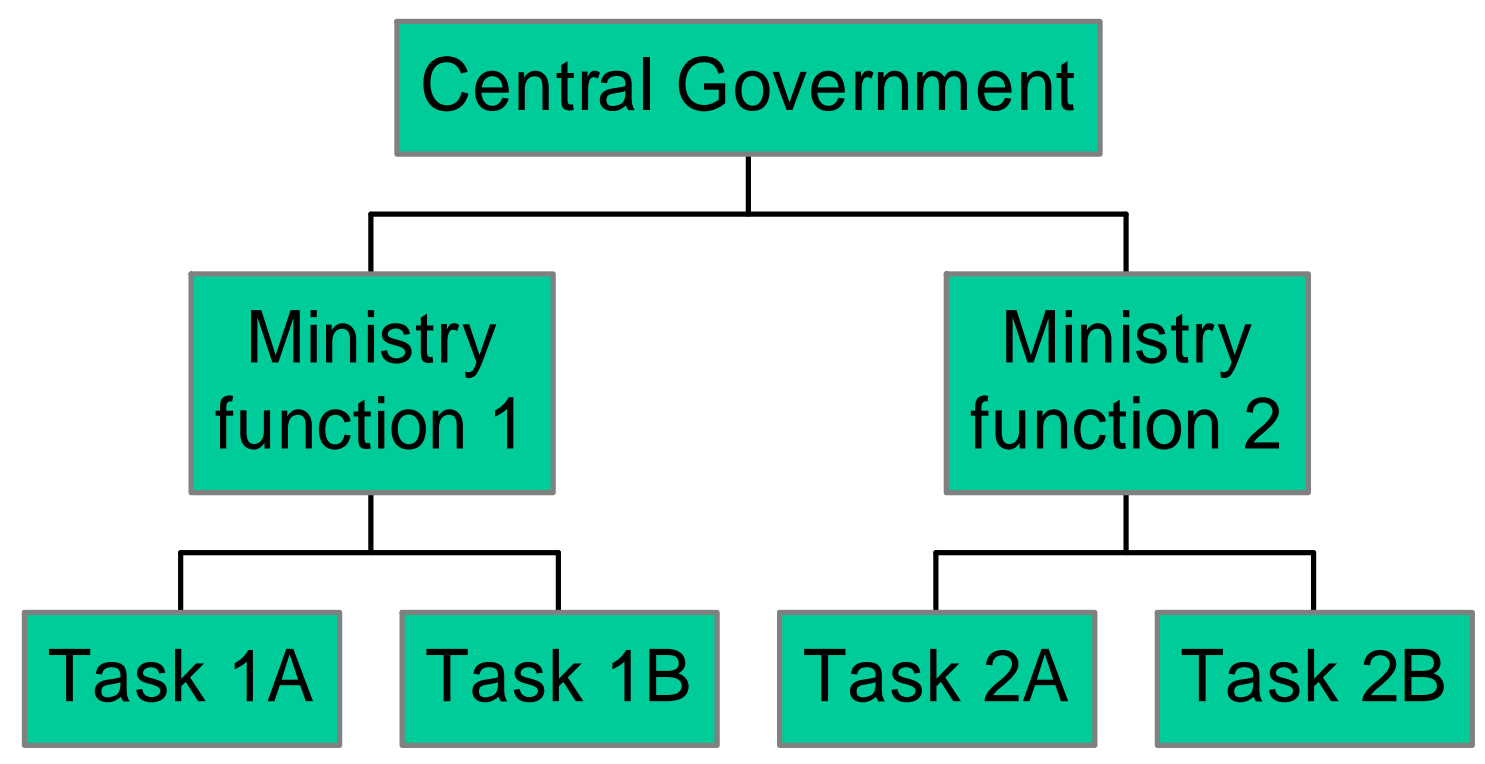

An M-form organization is set up along "regional lines." The middle officer $r(r=A, B)$ is responsible for collecting information about shocks in tasks $1 \mathrm{r}$ and 2r. Because the two tasks which require attribute matching are assigned to the same officer, the middle officers can match attributes between tasks $1 \mathrm{r}$ and $2 \mathrm{r}$ locally by themselves. The top officer provides a blueprint for change (and in 
section $\mathrm{V}$, the top officer also coordinates attribute compatibility). This type of organization can be represented by Figure 2:

\section{Figure 2. An M-form Organization}

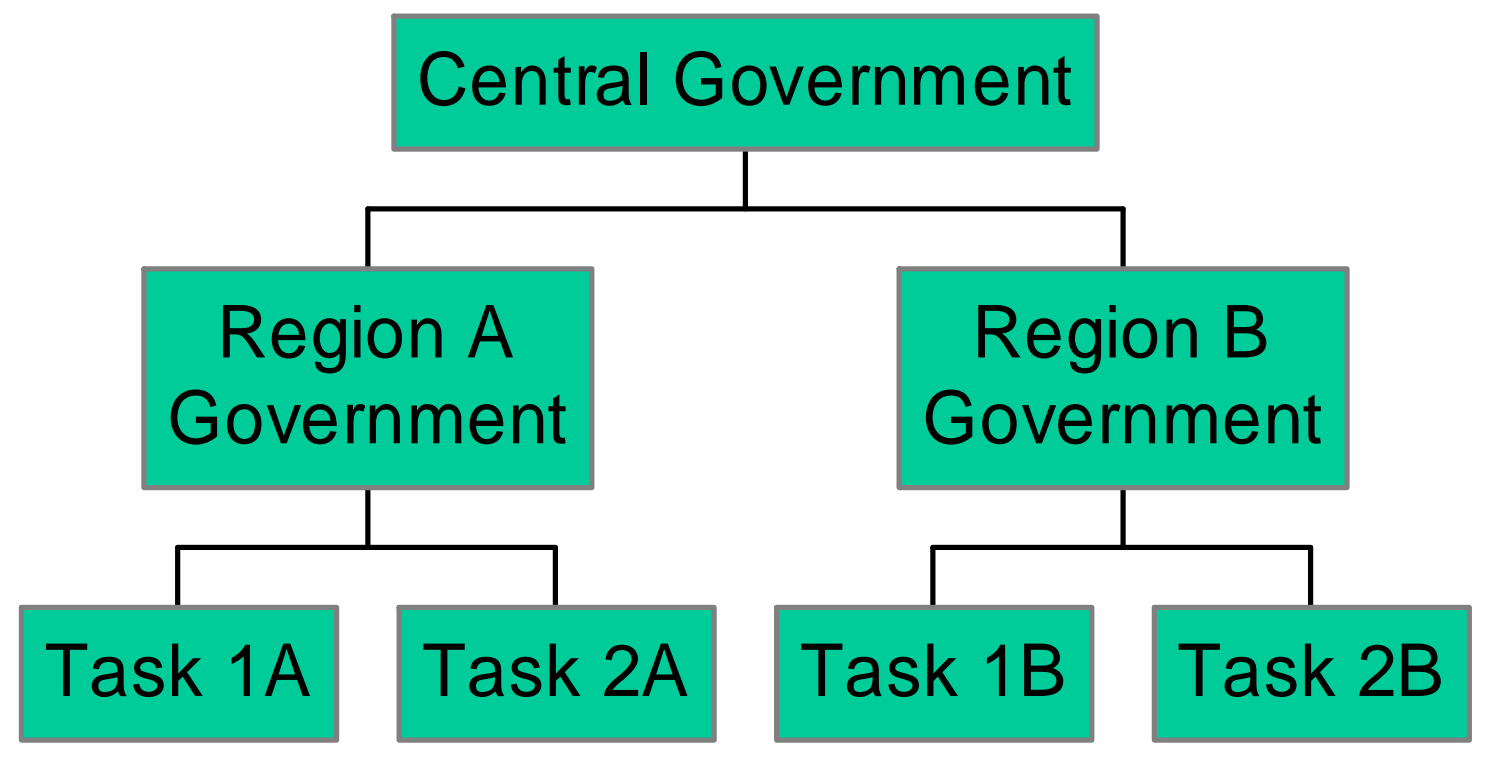

Under the M-form, setup costs must be incurred in each unit since attribute matching is done separately in each region unit. This leads to higher setup costs. For example, both officers need to be trained to coordinate the changes. In contrast, under the U-form, only the top officer matches attributes in a centralized way. Therefore, the setup cost is correspondingly smaller. ${ }^{9}$ For simplicity, we will assume that only one setup cost is required when only one officer coordinates.

We provide two examples below to illustrate our concept of coordination inside an organization as attribute matching.

\footnotetext{
${ }^{9}$ We note that in this framework, the M-form has an option to "mimic" the U-form by requiring regional managers to send messages to the top for coordination, but the U-form cannot "mimic" the M-form. However, when coordination on compatibility is added into the model in section $\mathrm{V}$, the two organizational forms will look symmetric.
} 


\section{Example 1. Coordinating innovations: manufacturing trucks}

Suppose there are two functions to produce trucks. Function 1 consists in supplying many types of bearings to the truck industry, and function 2 consists in manufacturing trucks. Because of differences in local road conditions, each region has its idiosyncratic preference for truck models (call them model A and model $\mathrm{B}$ trucks respectively). Task $1 \mathrm{r}$ is to produce bearings for a model $\mathrm{r}$ truck, and task $2 \mathrm{r}$ is to produce model $r$ trucks for region $r$, where $r=A$ and $B$.

The attributes of bearings and truck models should be matched to each other in order to produce

quality trucks. For example, the bearings should match the transmission equipment of the truck. If some attributes between the bearings and the truck are not matched, the truck cannot be made. Coordination consists in finding a solution to match bearings with parts of trucks. A technological innovation in transmission may make a truck more efficient, but it will change the technical requirements for bearings.

Suppose there is an innovation in the transmission system and the innovation outcome is uncertain. In the case where a new transmission system is good and every set of bearings is matched with every part of a truck, the new truck will be better than the old one. However, if one of the bearings does not fit with the corresponding part of the truck, the new truck will not work.

The firm can be organized into specialized units, a machine-building unit and a unit for producing bearings, with centralized matching of the attributes between bearings and trucks (U-form). It can also be organized along regional lines, where each region is responsible for producing one truck model (the Mform).

\section{Example 2. Coordinating reforms: enterprise restructuring and creation of a social safety net}

Suppose an economic reform consists of two components: enterprise restructuring (laying off excess workers) and creation of a social safety net. Task $1 \mathrm{r}$ is layoffs in region $r$ and task $2 \mathrm{r}$ is paying unemployment benefits through the social safety net in region $\mathrm{r}$, where $\mathrm{r}=\mathrm{A}$ and $\mathrm{B}$.

The attributes of enterprise restructuring are the number and individual characteristics of the laidoff workers, such as age, seniority, family composition, length of residence, sex, type of contract, current 
wage, history of employment, etc. The attributes of compensation from the social safety net are rules of eligibility, such as length of employment, special circumstances (veteran or not), status of enterprises, rules of benefits such as size and length, types of benefits (monetary or not), technical support of computers, administration, budget, etc. If some attributes of the two tasks are not matched, some laid-off workers may not be compensated appropriately.

If the reform is organized by specialized ministries (or committees), then each ministry is responsible for either enterprise restructuring or the social safety net, and the national government is responsible for matching the attributes between enterprise restructuring and the social safety net (the Uform). It is possible that there will be bad coordination between layoff policies and the creation of the social safety net, leading to riots. For example, the rules for eligibility set at the national level may be completely inappropriate in some important regions which have a concentration of older workers, if the national rule for pension eligibility does not make workers close to pension age eligible for any benefits.

If the reform is organized by the regions, each regional government is responsible for matching the attributes between enterprise restructuring and the social safety net in its own region (the M-form). Under this type of organization, layoff policies and the institution of social safety nets can be better coordinated within each region so that riots can be prevented.

\section{Coordination, Experimentation, and Organizational Flexibility}

In this section, we compare the $\mathrm{M}$-form and the $\mathrm{U}$-form assuming that only one blueprint is available in each time period. Under both organizational forms, the payoff from the status quo (i.e., no reform) is 1 for each period, and thus the status quo discounted payoff is $1 /(1-\delta)$.

Consider first the situation in which an organization starts a reform in both of its units and continues in that way afterwards. Under the M-form, every unit officer will be responsible for matching the attributes of the two tasks within his unit. With perfect local information, attribute matching under the M-form will be performed perfectly. If a program is good, which happens with probability $\mathrm{p}$, the total payoff from the two units is $\mathrm{R} /(1-\delta)$. If a program is bad, which happens with probability $1-\mathrm{p}$, the current 
payoff is zero, and a new program will be tried in the next period. Therefore, the expected payoff of continued reform in an M-form is

$$
\pi_{\mathrm{m} 2}=\mathrm{pR} /(1-\delta)+(1-\mathrm{p}) \delta \pi_{\mathrm{m} 2}
$$

from which we obtain

$$
\pi_{\mathrm{m} 2}=\mathrm{pR} /\{(1-\delta)[1-(1-\mathrm{p}) \delta]\} .
$$

On the cost side, in period $1,2 \mathrm{C}$ is paid because two officers are involved in coordination. With probability $\mathrm{p}$, the program is good so no more costs need to be paid afterwards. But with a probability 1$\mathrm{p}$ the program is bad, which is discovered after one period of change. Then a new program is tried in the next period. Because the officers need to be retrained for matching attributes, an additional cost of $2 \mathrm{C}$ is paid in the next period, and so on. Therefore, we should have

$$
\mathrm{c}_{\mathrm{m} 2}=2 \mathrm{C}+\delta(1-\mathrm{p}) \mathrm{c}_{\mathrm{m} 2}
$$

from which we derive

$$
\mathrm{c}_{\mathrm{m} 2}=2 \mathrm{C} /[1-(1-\mathrm{p}) \delta]
$$

Under the U-form, the top officer is responsible for coordinating the four tasks. He thus receives four messages through noisy communication, each corresponding to one of the four tasks. When the program is bad (with probability 1-p), the innovation fails, and a new program will be tried in the next period. If the program is good (with probability p), there are three possibilities: (i) With probability $\lambda^{4}$, coordination is successful for both regions A and B. (ii) With probability $\left(1-\lambda^{2}\right)^{2}$, coordination fails in both $\mathrm{A}$ and $\mathrm{B}$. This will give the same outcome as a bad program. (iii) With probability $2 \lambda^{2}\left(1-\lambda^{2}\right)$, coordination for one of the two regions is successful. In this case, knowing that the program is good, the top officer will use the same program for the region for which the coordination failed and solve only the attribute matching problem in the next period. Hence, the payoff of reform under the U-form is

$$
\pi_{\mathrm{u} 2}=\mathrm{p}\left\{\lambda^{4} \mathrm{R} /(1-\delta)+2 \lambda^{2}\left(1-\lambda^{2}\right)[\mathrm{R} /[2(1-\delta)]+\delta \pi]+\left(1-\lambda^{2}\right)^{2} \delta \pi_{\mathrm{u} 2}\right\}+(1-\mathrm{p}) \delta \pi_{\mathrm{u} 2},
$$

where $\pi$ is the expected payoff of change for one region for a good program:

$$
\pi=\lambda^{2} \mathrm{R} /[2(1-\delta)]+\left(1-\lambda^{2}\right) \delta \pi,
$$

which implies that 


$$
\pi=\lambda^{2} \mathrm{R} /\left\{2(1-\delta)\left[1-\left(1-\lambda^{2}\right) \delta\right]\right\} .
$$

Using the above recursive formula of $\pi$, we obtain

$$
\begin{gathered}
\pi_{\mathrm{u} 2}=\mathrm{p}\left\{2 \lambda^{2}\left[\lambda^{2} \mathrm{R} / 2(1-\delta)+\left(1-\lambda^{2}\right) \mathrm{R} / 2(1-\delta)+\left(1-\lambda^{2}\right) \delta \pi+\left(1-\lambda^{2}\right) \delta \pi-\left(1-\lambda^{2}\right) \delta \pi\right] /\left\{1-\delta\left[\mathrm{p}\left(1-\lambda^{2}\right)^{2}+(1-\mathrm{p})\right]\right\}\right. \\
=2 \mathrm{p}\left[\lambda^{2} \mathrm{R} / 2(1-\delta)+\lambda^{2}\left(1-\lambda^{2}\right) \delta \pi+\left(1-\lambda^{2}\right) \delta \pi-\left(1-\lambda^{2}\right) \delta \pi\right] /\left\{1-\delta\left[\mathrm{p}\left(1-\lambda^{2}\right)^{2}+(1-\mathrm{p})\right]\right\} \\
=2 \mathrm{p} \pi\left[1-\left(1-\lambda^{2}\right)^{2} \delta\right] /\left\{1-\delta\left[\mathrm{p}\left(1-\lambda^{2}\right)^{2}+(1-\mathrm{p})\right]\right\} \\
=\lambda^{2} \mathrm{pR}\left[1-\left(1-\lambda^{2}\right)^{2} \delta\right] /\left\{(1-\delta)\left[1-\left(1-\lambda^{2}\right) \delta\right]\left[1-\delta\left[\mathrm{p}\left(1-\lambda^{2}\right)^{2}+(1-\mathrm{p})\right]\right]\right\} .
\end{gathered}
$$

On the cost side, when a reform is introduced in period 1 , only a setup $\cos \mathrm{C}$ is paid (instead of $2 \mathrm{C}$ in the $\mathrm{M}$-form) because only the top officer matches attribute. With probability $1-\mathrm{p}$ the program is bad, which is discovered after one period. With probability $\mathrm{p}\left(1-\lambda^{2}\right)^{2}$ the program is good but coordination fails for both regions. In both cases, a new program is tried in the next period. When the program is good and coordination is successful for at least one of the two regions, the program will be known to be good. In such a case, no new setup cost needs to be paid in the next period. Indeed, the top officer has already been trained for that program and he has been able to successfully coordinate attribute matching for one region. Under this assumption, we have:

$$
\mathrm{c}_{\mathrm{u} 2}=\mathrm{C}+\delta\left[\mathrm{p}\left(1-\lambda^{2}\right)^{2}+(1-\mathrm{p})\right] \mathrm{c}_{\mathrm{u} 2},
$$

from which we obtain

$$
\mathrm{c}_{\mathrm{u} 2}=\mathrm{C} /\left\{1-\left[\mathrm{p}\left(1-\lambda^{2}\right)^{2}+1-\mathrm{p}\right] \delta\right\}
$$

Lemma 1: (1) $\pi_{\mathrm{u} 2} \leq \pi_{\mathrm{m} 2}$, and $\pi_{\mathrm{u} 2}$ increases in $\lambda$ and reaches $\pi_{\mathrm{m} 2}$ at $\lambda=1$.

(2) $\mathrm{c}_{\mathrm{u} 2}$ decreases in $\lambda$, and $\mathrm{c}_{\mathrm{u} 2}<\mathrm{c}_{\mathrm{m} 2}$ if and only if $\delta\left(1-\mathrm{p}+2 \mathrm{p}\left(1-\lambda^{2}\right)^{2}\right)<1$.

When communication between the middle officers and the top officer is perfect, the two organizational forms are equivalent in the expected payoffs. However, when communication is not perfect and because there is no communication problem under the $\mathrm{M}$-form, $\mathrm{M}_{2}$ always has a higher expected benefit than $\mathrm{U}_{2}$. Under $\mathrm{U}_{2}$, costs decrease with $\lambda$ because better communication decreases the probability of failure with change, thereby lowering the probability of drawing new experiments and 
incurring repeated setup costs. The trade-off between costs under $\mathrm{M}_{2}$ and $\mathrm{U}_{2}$ is also related to the quality of communication under $\mathrm{U}_{2}$. The latter avoids the costs of duplication but bad communication leads to a higher failure rate, possibly leading to higher total costs because of the need to draw more experiments before achieving success.

We define the expected net payoff under the M-form and U-form, respectively,

$$
\mathrm{M}_{2}=\pi_{\mathrm{m} 2}-\mathrm{c}_{\mathrm{m} 2}
$$

and

$$
\mathrm{U}_{2}=\pi_{\mathrm{u} 2}-\mathrm{c}_{\mathrm{u} 2}
$$

Proposition 1: Comparing the M-form and the U-form:

(1) the M-form has a higher expected net benefit than the U-form if communication quality $(\lambda)$ is low enough: for $\mathrm{p}$ and $\mathrm{C}$ given, there exists $\lambda \in(0,1)$ for which $\mathrm{M}_{2}>\mathrm{U}_{2}$ if and only if $\lambda<\lambda$.

(2) the U-form has a higher expected net benefit than the M-form if the setup cost (C) is high enough: when $\mathrm{c}_{\mathrm{u} 2}<\mathrm{c}_{\mathrm{m} 2}$ and for $\mathrm{p}$ and $\lambda$ given, there exists $\mathrm{C}>0$ such that $\mathrm{U}_{2}>\mathrm{M}_{2}$ and if only if $\mathrm{C}>\mathrm{C}$.

Proposition 1 formulates the basic tradeoff between coordination and scale economies in implementing changes under the $\mathrm{M}$-form and the $\mathrm{U}$-form. The $\mathrm{U}$-form has an advantage in scale economies because the top officer is responsible for coordination in the entire organization. The organization thus saves on setup costs but the U-form has disadvantages in coordination because local information is communicated imperfectly from the local officers to the top officer. In contrast, the Mform has better coordination because officers can make better use of local information for coordination purposes, but it suffers from disadvantages in scale economies: it pays twice the setup costs because two local officers are responsible for attribute matching instead of one top officer. ${ }^{10}$ In view of this trade-off,

\footnotetext{
${ }^{10}$ In Bolton and Farrell (1990) it is coordination failure (in the context of multiple equilibria) that creates duplication costs. In our model, coordination is defined as attribute matching inside an organization while the duplication of setup costs is related to the lack of scale economies or specialization (on the latter point, see also Becker and Murphy (1992)). Here, there is no causality between coordination failure and the duplication of setup costs.
} 
the M-form will be more efficient than the U-form when communication quality is relatively low, or when the setup cost is relatively small.

We next introduce the possibility that an organization starts a program for change in one of its two units and later extends it to another unit, conditional on successful implementation in the first unit. In other words, we look at the possibility of experimentation in implementing changes.

Under the M-form, suppose at first that a program is introduced in unit A whereas the status quo is maintained in unit B. If the program is a good one, the first period payoff is $(\mathrm{R}+1) / 2$. In the second period, the same program is then used in unit B. From then on, the payoff is always R per period. However, if the program is bad, the experimenting unit A will get 0 payoff and the non-experimenting unit $\mathrm{B}$ will get $1 / 2$. In this case, a new experiment in unit A will take place again in the next period. Therefore, the expected payoff of the M-form with experimentation is given by

$$
\pi_{\mathrm{m} 1}=\mathrm{p}\{\mathrm{R} / 2(1-\delta)+1 / 2+\delta \mathrm{R} / 2(1-\delta)\}+(1-\mathrm{p})\left\{1 / 2+\delta \pi_{\mathrm{m} 1}\right\},
$$

that is,

$$
\pi_{\mathrm{m} 1}=\mathrm{p}[\mathrm{R}+(1-\delta)+\delta \mathrm{R}] / 2(1-\delta)+(1-\mathrm{p})\left\{1 / 2+\delta \pi_{\mathrm{m} 1}\right\}
$$

Therefore, we obtain

$$
\pi_{\mathrm{m} 1}=[\mathrm{pR}(1+\delta)+(1-\delta)] /\{2(1-\delta)[1-(1-\mathrm{p}) \delta]\} .
$$

The setup cost in the first period is $\mathrm{C}$ because only unit A's officer does attribute matching. If the program is good, unit B will use the same program in period 2 and another cost $C$ will be paid in period 2 because unit B's officer needs to match attributes according to local conditions. Unit B thus imitates unit A's success, but does not copy it, since local coordination is still required to introduce the successful blueprint. With probability $1-\mathrm{p}$, the program is bad and a new blueprint must be tried. We are then back to the situation of period 1 . Hence we get,

$$
\mathrm{c}_{\mathrm{m} 1}=\mathrm{C}+\delta\left[\mathrm{pC}+(1-\mathrm{p}) \mathrm{c}_{\mathrm{m} 1}\right]
$$

which implies that

$$
\mathrm{c}_{\mathrm{m} 1}=(1+\mathrm{p} \delta) \mathrm{C} /[1-(1-\mathrm{p}) \delta] .
$$

We define the net expected payoff under the M-form with an experimentation strategy as 


$$
\mathrm{M}_{1}=\pi_{\mathrm{m} 1}-\mathrm{c}_{\mathrm{m} 1}
$$

Because of Assumption 1, pR > 1, we have:

Lemma 2: (1) $\pi_{\mathrm{m} 1}<\pi_{\mathrm{m} 2}$, and $\mathrm{c}_{\mathrm{m} 1}<\mathrm{c}_{\mathrm{m} 2}$.

(2) $\mathrm{dM}_{2} / \mathrm{dp}>\mathrm{dM}_{1} / \mathrm{dp}>0$.

Both the expected net benefits under $\mathrm{M}_{1}$ and $\mathrm{M}_{2}$ monotonically increase with $\mathrm{p}$. By Lemma 2, we can define $\mathrm{p}_{\mathrm{m} 2} *$ as the probability such that $\mathrm{M}_{2}=1 /(1-\delta)$ and $\mathrm{p}_{\mathrm{m} 1} *$ as the probability such that $\mathrm{M}_{1}=1 /(1-$ $\delta)$, where $1 /(1-\delta)$ is the status quo payoff. Then, for all $\mathrm{p}>\mathrm{p}_{\mathrm{m} 1}{ }^{*}, \mathrm{M}_{1}$ has higher expected net payment than the status quo; and for all $\mathrm{p}>\mathrm{p}_{\mathrm{m} 2}{ }^{*}, \mathrm{M}_{2}$ has higher expected net payment than the status quo. Let $\mathrm{p}$ be the probability such that $\mathrm{M}_{1}=\mathrm{M}_{2}$. The following proposition compares two reform strategies in the M-form: experimentation and non-experimentation or immediate full change (innovation introduced in both units simultaneously).

Proposition 2: (1) $\mathrm{p}_{\mathrm{m} 1} *<\mathrm{p}_{\mathrm{m} 2} *<\mathrm{p}<1$. That is, $\mathrm{M}_{1}>\mathrm{M}_{2}$ if and only if the uncertainty $\mathrm{p}<\mathrm{p}$, and experimentation dominates the status quo while immediate full change does not for $\mathrm{p} \varepsilon\left(\mathrm{p}_{\mathrm{m} 1}{ }^{*}, \mathrm{p}_{\mathrm{m} 2}{ }^{*}\right)$.

(2) for $\mathrm{p}$ given, experimentation yields a higher expected net benefit if and only if setup $\operatorname{cost} \mathrm{C}>\mathrm{C}=(\mathrm{pR}-$ 1)/2(1-p $\delta)$.

Proposition 2 demonstrates the following tradeoff. Experimentation provides an option value of waiting to learn about the quality of the blueprint before implementing the full program for change, but it comes at the cost of delaying a successful full change in the whole organization. The difference in the expected net benefits between experimentation and immediate full change under the $\mathrm{M}$-form is given by

$$
\mathrm{M}_{1}-\mathrm{M}_{2}=\{\mathrm{C}(1-\mathrm{p} \delta)-(\mathrm{pR}-1) / 2\} /[1-\delta(1-\mathrm{p})]
$$

The first term $\mathrm{C}(1-\mathrm{p} \delta)$ in the numerator indicates the option value of waiting to learn about $\mathrm{p}$ before sinking $\mathrm{C}$ in an additional unit. This option value of waiting increases as $\mathrm{p}$ decreases, i.e. when there is 
greater uncertainty about the value of the blueprint. Therefore, experimentation can save on setup costs because of the option value of early reversal of a bad blueprint (Dewatripont and Roland, 1995). The second term in the numerator (pR-1)/2 (which is positive by Assumption 1) shows the cost of delaying experimentation in one unit under $M_{1}$. This cost increases with $p$. Clearly, when $p=1, M_{2}>M_{1}$ since the numerator becomes $\mathrm{C}(1-\delta)-(\mathrm{R}-1) / 2$, which is smaller than zero by Assumption 2. $\mathrm{M}_{2}$ continues to dominate $\mathrm{M}_{1}$ until $\mathrm{p}$ falls below $\mathrm{p}$. In particular, when $\mathrm{p}$ falls further into the region of $\left[\mathrm{p}_{\mathrm{m} 1}{ }^{*}, \mathrm{p}_{\mathrm{m} 2}{ }^{*}\right], \mathrm{M}_{1}$ is greater than the status quo but $\mathrm{M}_{2}$ is not.

We now analyze the possibility of experimentation under the U-form. Without loss of generality, we assume that at first a blueprint is implemented in unit 1 whereas unit 2 maintains the status quo. In line with our assumptions, the top officer does the attribute matching for regions A and B.

We assume that the quality of the program (good or bad) can be discovered even when the change is implemented for only one task. We further assume that in order to match attributes of two tasks, whenever there is a change in at least one task, information (and thus communication) about the attributes of both tasks is needed. This is because even if a change is introduced in one task, attribute matching always involves another task. Therefore, under U-form with change in only one unit, all messages corresponding to the four tasks must be communicated by the two middle officers to the top officer.

After one period of experimentation in one unit, if a program is bad, the innovation fails, and in the next period a new program will be tried. If a program is good, there are three possible outcomes: (i) With probability $\lambda^{4}$ attribute matching is achieved for both regions A and B. Then in the next period, the same program is used in both units and the final payoff will only depend on the outcome of attribute matching. (ii) With probability $\left(1-\lambda^{2}\right)^{2}$, coordination is bad for both A and B. This will give the same outcome as a bad program and a new program will be tried in the next period. (iii) With probability $2 \lambda^{2}\left(1-\lambda^{2}\right)$, coordination for A or B is successful which will reveal that the program is good. In the next period, the two units will use the same program and the payoff for the earlier failed region will depend on the outcome of attribute matching. Hence, the expected payoff of the U-form with experimentation is

$$
\pi_{\mathrm{u} 1}=\mathrm{p}\left\{\lambda^{4}[(\mathrm{R}+1) / 2+\delta 2 \pi]+2 \lambda^{2}\left(1-\lambda^{2}\right)[(\mathrm{R}+1) / 4+\delta 2 \pi]+\left(1-\lambda^{2}\right)^{2} \delta \pi_{\mathrm{u} 1}\right\}+(1-\mathrm{p}) \delta \pi_{\mathrm{u} 1},
$$


where $\pi$ is, as above, the expected payoff of reform in one region when the program is good, as defined above. Hence, we obtain

$$
\pi_{\mathrm{u} 1}=\mathrm{p}\left\{\lambda^{4}[(\mathrm{R}+1) / 2+\delta 2 \pi]+2 \lambda^{2}\left(1-\lambda^{2}\right)[(\mathrm{R}+1) / 4+\delta 2 \pi]\right\} /\left\{1-\delta\left[\mathrm{p}\left(1-\lambda^{2}\right)^{2}+(1-\mathrm{p})\right]\right\} .
$$

Under the U-form, the setup cost is the same as reform without experimentation. This is because coordination is done at the top and always requires four messages to be sent to the top officer who must be trained to do the appropriate coordination. We also assume that the setup cost $\mathrm{C}$ enables the officer to implement both partial and full change. ${ }^{11}$ Therefore,

$$
\mathrm{c}_{\mathrm{u} 1}=\mathrm{c}_{\mathrm{u} 2}=\mathrm{C} /\left\{1-\left[\mathrm{p}\left(1-\lambda^{2}\right)^{2}+1-\mathrm{p}\right] \delta\right\} .
$$

We define the net expected payoff under a U-form with experimentation as

$$
\mathrm{U}_{1}=\pi_{\mathrm{u} 1}-\mathrm{c}_{\mathrm{u} 1} \text {. }
$$

Proposition 3: Under the U-form, experimentation is always dominated by immediate full change:

$$
\pi_{\mathrm{u} 1}<\pi_{\mathrm{u} 2}, \mathrm{c}_{\mathrm{u} 1}=\mathrm{c}_{\mathrm{u} 2} \text {, and } \mathrm{U}_{1}<\mathrm{U}_{2} .
$$

The U-form organization does not benefit from experimentation because of the complications involved in coordinating activities. While the setup cost is not lower as with full change, there is no additional benefit in coordination and there are only costs in delaying expected benefits.

Since partial innovation in the U-form never occurs in equilibrium, it is useful to give an example. Think of changes in computer software where task 1 represents change in the operating system and task 2 change in a word processor. Experimentation under U-form in this case means, for example, first changing the operating system (from DOS to windows 95), and then changing the word processor (from WordPerfect 5.1 to WordPerfect 8). In this example, partial innovation involves first matching the attributes of the old word processor with the new operating system (via a solution like the "DOS prompt")

\footnotetext{
${ }^{11}$ It would be reasonable to assume that the setup cost should be incurred twice, a first time when partial innovation is tried and a second time when the full innovation is implemented since the nature of the coordination is different in both cases. This assumption would however only reinforce the result of proposition 3.
} 
and then matching the attributes of the new operating system with the new word processor. In terms of difficulty of coordination, one gains nothing from this partial innovation and one might just as well directly introduce both changes. This is the message of proposition 3 .

The flexibility of the M-form yields an advantage over the U-form:

Proposition 4: (1) the U-form has higher expected net benefits than the M-form if the quality of communication $\lambda$ is close enough to 1 .

(2) Experimentation under the M-form yields higher expected net benefits than immediate full change under either $\mathrm{M}$-form or $\mathrm{U}$-form if the quality of communication $\lambda$ is small enough and either $\mathrm{p}<\underline{\mathrm{p}}$ or $\mathrm{C}>$ $\mathrm{C}=(\mathrm{pA}-1) / 2(1-\mathrm{p} \delta)$.

When communication quality is high, the U-form will dominate because of its advantages in scale economies. The more interesting results are those on the flexibility of the M-form. From Propositions 2 and 3 we know that when the probability of success is low or the setup cost is high, the M-form has the option of experimentation while experimentation has no value to the U-form. In such a case, the M-form can do better than the U-form, provided communication quality is low enough.

\section{Coordination and Parallel Experimentation}

In this section we assume that two independent blueprints are available at a given time. This introduces a possibility that both blueprints are tried simultaneously in two units in the M-form, yielding net benefits denoted $\mathrm{M}_{11}$. If there is one successful experiment in one unit, it can be copied costlessly in the other unit, as in the previous section. Under this strategy:

$$
\pi_{\mathrm{m} 11}=\mathrm{p}^{2} \mathrm{R} /(1-\delta)+2(1-\mathrm{p}) \mathrm{p}\{\mathrm{R} / 2(1-\delta)+\delta \mathrm{R} / 2(1-\delta)\}+(1-\mathrm{p})^{2} \delta \pi_{\mathrm{m} 11}
$$

from which we obtain:

$$
\pi_{\mathrm{m} 11}=\left\{\mathrm{R}\left(\mathrm{p}^{2}+\mathrm{p}(1-\mathrm{p})(1+\delta)\right)\right\} /(1-\delta)\left[1-\delta(1-\mathrm{p})^{2}\right]
$$

Similarly for the cost: 


$$
c_{\mathrm{m} 11}=2 \mathrm{C}+2(1-\mathrm{p}) \mathrm{p} \delta \mathrm{C}+(1-\mathrm{p})^{2} \delta \mathrm{c}_{\mathrm{m} 11}
$$

from which we obtain:

$$
\mathrm{c}_{\mathrm{m} 11}=2 \mathrm{C}[1+\delta \mathrm{p}(1-\mathrm{p})] /\left[1-\delta(1-\mathrm{p})^{2}\right]
$$

Lemma 3: Under the M-form, parallel experimentation always yields higher expected benefits and lower expected costs than immediate full change:

$$
\pi_{\mathrm{m} 11}>\pi_{\mathrm{m} 2} \text { and } \mathrm{c}_{\mathrm{m} 11}<\mathrm{c}_{\mathrm{m} 2} .
$$

If two independent blueprints are available, then it is always better to try one in each unit rather than one in both units. Why do two independent experiments always give higher expected benefits than two perfectly correlated experiments? In the first period, the two will give the same expected outcome but since two independent experiments have a higher probability of at least one success, success will tend to be implemented earlier with independent experiments. Similarly, the reason for the lower costs with two independent experiments is that under the latter, the probability that no further cost will be paid next period is $1-(1-p)^{2}$ whereas it is only 1-p under two perfectly correlated experiments.

Lemma 4: Under the M-form: (1) parallel experimentation has both higher expected benefits and expected costs than experimentation in one unit:

$$
\pi_{\mathrm{m} 11}>\pi_{\mathrm{m} 1} \text { and } \mathrm{c}_{\mathrm{m} 11}>\mathrm{c}_{\mathrm{m} 1} .
$$

(2) parallel experimentation has higher net expected benefits than experimentation in one unit if and only if

$$
\mathrm{C}<\mathrm{C}^{1}=\mathrm{pA}\left(1+\delta(1-\mathrm{p})^{2}\right) / 2[1-\delta+\delta \mathrm{p}(1-\mathrm{p})(1-\delta(1-\mathrm{p}))]+\left(1-\delta(1-\mathrm{p})^{2}\right)
$$

The higher benefit of parallel experimentation compared to experimentation in one unit is due to two reasons. First, it has a higher first period expected benefit $(p R>p R / 2+1 / 2$ because $p R>1$ (by Assumption 1). Second, the former has a higher probability (i.e., 1-(1-p $\left.)^{2}\right)$ than the latter (i.e., 1-p) to 
have a known good blueprint from the second period onward.

The reason why parallel experimentation has higher costs than experimentation in one unit is that under the former at least $2 \mathrm{C}$ always has to be paid out up front. Note that both $\mathrm{c}_{\mathrm{m} 11}$ and $\mathrm{c}_{\mathrm{m} 1}$ decline with p. The former declines faster than the latter as under $\mathrm{M}_{11}$ learning about a success is faster. Nevertheless, when $\mathrm{p}$ approaches $1, \mathrm{c}_{\mathrm{m} 11}$ approaches $2 \mathrm{C}$ while $\mathrm{c}_{\mathrm{m} 1}$ approaches $\mathrm{C}(1+\delta)$, which still remains smaller.

Looking at the difference $\left(\mathrm{M}_{11}-\mathrm{M}_{1}\right)$, we have:

$$
\begin{aligned}
& \mathrm{d}\left(\mathrm{M}_{11}-\mathrm{M}_{1}\right) / \mathrm{dp}=\mathrm{R}\left(1+\delta(1-\mathrm{p})^{2}\right)-2 \mathrm{pR} \delta(1-\mathrm{p})-2 \mathrm{C}\left[\delta(1-2 \mathrm{p})(1-\delta(1-\mathrm{p}))+\delta^{2} \mathrm{p}(1-\mathrm{p})\right]-2 \delta(1-\mathrm{p}) \\
& =\mathrm{R}(1+\delta(1-\mathrm{p})(1-3 \mathrm{p}))-2 \mathrm{C} \delta[1-2 \mathrm{p}-\delta(1-\mathrm{p})(1-3 \mathrm{p})]-2 \delta(1-\mathrm{p}) \\
& =\delta(1-\mathrm{p})(1-3 \mathrm{p})(\mathrm{R}+2 \mathrm{C} \delta)+\mathrm{R}-2 \mathrm{C} \delta(1-2 \mathrm{p})-2 \delta(1-\mathrm{p})
\end{aligned}
$$

There is thus a non-linear relationship between $\mathrm{p}$ and $\left(\mathrm{M}_{11}-\mathrm{M}_{1}\right)$. Comparing the net benefits in $\mathrm{M}_{11}$ and $\mathrm{M}_{1}$ is therefore complicated. But one sees intuitively that the lower $\mathrm{C}$ is relative to $\mathrm{A}$, the higher the advantage of $\mathrm{M}_{11}$ over $\mathrm{M}_{1}$, and vice versa.

We can now summarize the comparison between various organizational forms:

Proposition 5: (1) the U-form has higher expected net benefits than all other organizational forms if $\lambda=1$ and either $\mathrm{p}=1$ or $\mathrm{C}>\mathrm{C}^{2}=\mathrm{pR} \delta(1-\mathrm{p})^{2} /\left[1-\delta(1-\mathrm{p})^{2}(1+2 \delta \mathrm{p})\right]$.

(2) experimentation in one unit under the M-form dominates if $\lambda$ is low enough and $C>C^{1}$.

(3) parallel experimentation under the $\mathrm{M}$-form dominates if either $\lambda=1$ but $\mathrm{C}<\mathrm{C}_{1}$ or if $\lambda$ is low enough, $\mathrm{p}>\mathrm{p}$ or $\mathrm{C}<\mathrm{C}^{1}$.

The U-form dominates when communication quality is high and either setup costs are high or there is no uncertainty about the experiment. The M-form with experimentation in one unit dominates when communication quality is low and setup costs are high; it dominates with parallel experimentation either when costs are low enough (in which case it dominates the U-form) or when communication quality is low enough but setup costs are sufficiently low and the probability of success sufficiently high (in which case it dominates partial experimentation). A major difference between Propositions 4 and 5 is 
as follows. When parallel experimentation is not available, the flexibility advantage of the M-form can be achieved when setup costs are high and the probability of success is low, whereas when parallel experimentation is available an additional flexibility advantage of the M-form can be achieved when setup costs are low and the probability of success is high.

\section{Coordination on Attribute Compatibility}

In this section we extend our coordination concept to incorporate attribute compatibility between tasks $\mathrm{iA}$ and $\mathrm{iB}(\mathrm{i}=1,2)$. We will focus on the trade-off between better matching under the $\mathrm{M}$-form and better compatibility under the U-form. Therefore, we abstract from setup costs and assume $\mathrm{C}=0$ to make this trade-off clear. We assume that the dimension of attributes for which compatibility between tasks iA and $\mathrm{iB}$ is required is of order $\mathrm{k}$. We assume that $\mathrm{k} \leq 1$, which represents the idea that the attributes to be made compatible typically have a lower dimension than the attributes to be matched. Indeed, remember that compatibility concerns attributes of similar tasks which in general are not matched together but rather act as substitutes for one another. Whereas matching is the rule for complementary parts, substitution is not necessarily the rule for similar parts.

Under the U-form, unit officers coordinate compatibility between tasks iA and iB within each unit. Because they do not need to communicate with other officers, compatibility will be achieved perfectly inside each unit of the U-form. Under the M-form, unit officers must send messages about shocks concerning attribute compatibility to the top officer who is responsible for attribute compatibility. The probability of a message being correctly received by the top officer is $\lambda^{\mathrm{k}}$.

In the example of innovation in truck manufacturing, bearings for the model A truck should be compatible with bearings for the model B truck, and similarly for the transmission systems for the two models. Otherwise, even if the two trucks run well, the lack of service (or higher costs of inventories) due to the incompatibility of the two models will lower the value of the new truck. In the example of enterprise restructuring and the social safety net, if the layoff policies in the two regions are not compatible, inefficient close-downs may occur. Similarly, if the rules of eligibility for compensations in 
the social safety net are not compatible across regions, sub-optimal labor mobility may result.

We assume the following payoff structure when compatibility is required in addition to attribute matching. Again, let the status quo payoff be 1/2. Consider the payoffs for region A under reform (payoffs for B are defined symmetrically). Suppose the blueprint is good, then (i) with change in task 1A but not in task $2 \mathrm{~A}$ (or change in task $2 \mathrm{~A}$ but not in task $1 \mathrm{~A}$ ), the payoff is $(\mathrm{R}+1) / 4$ if the attributes between $1 \mathrm{~A}$ and $2 \mathrm{~A}$ are matched, and the attributes between $1 \mathrm{~A}$ and $1 \mathrm{~B}$ and those between $2 \mathrm{~A}$ and $2 \mathrm{~B}$ are compatible, otherwise 0 ; and (ii) with reform in both tasks $1 \mathrm{~A}$ and $2 \mathrm{~A}$, the payoff is $\mathrm{R} / 2$ if the attributes between $1 \mathrm{~A}$ and $2 \mathrm{~A}$ are matched, and the attributes between $1 \mathrm{~A}$ and $1 \mathrm{~B}$ and those between $2 \mathrm{~A}$ and $2 \mathrm{~B}$ are compatible, otherwise 0 . If the program is bad, then the payoff is always $0 .{ }^{12}$

Under the U-form, because coordination on compatibility is perfect, the expected payoff is the same as in the case without attribute compatibility analyzed in section III. But, the expected payoffs of the M-form will be different. Local officers will continue to make perfect attribute matching in both units. In the M-form without experimentation, the top officer now receives four messages from the two local officers about compatibility shocks. Therefore, we can write down the expected payoff under Mform as

$$
\pi_{\mathrm{m} 2}=\mathrm{p}\left\{\lambda^{4 \mathrm{k}} \mathrm{R} /(1-\delta)+\delta\left(1-\lambda^{4 \mathrm{k}}\right) \pi_{\mathrm{m} 2}\right\}+(1-\mathrm{p}) \delta \pi_{\mathrm{m} 2},
$$

from which we obtain:

$$
\pi_{\mathrm{m} 2}=\mathrm{pR} \lambda^{4 \mathrm{k}} /\left\{(1-\delta)\left[1-\delta\left[\mathrm{p}\left(1-\lambda^{4 \mathrm{k}}\right)+(1-\mathrm{p})\right]\right]\right\} .
$$

Now consider the experimentation approach in the M-form. Suppose a blueprint is tried in unit A, and unit B remains unchanged. With probability 1-p, the program is bad. Therefore, the payoff in A is 0 . However, with probability $\lambda^{4 \mathrm{k}}$, compatibility is achieved and the unreformed unit B produces payoff $1 / 2$. With probability $1-\lambda^{4 k}$, the payoff in B is 0 due to compatibility failure. In period 2 , we are back to

\footnotetext{
${ }^{12}$ The assumption here that the payoff is zero when attributes between tasks iA and iB are not compatible is made for simplicity. It makes the disadvantage of the M-form in coordinating compatibility the highest. In addition, the assumption that compatibility is not achieved if any one message is wrong also simplifies the analysis. Relaxing either of these assumptions will not change our results qualitatively.
} 
the situation of period 1 . With probability $\mathrm{p}$, the program is good. In this case, with probability $\lambda^{4 \mathrm{k}}$, compatibility is achieved, and the total payoff is $(\mathrm{R}+1) / 2$. In the next period, the same reform program is used in B. However, the officers in the two regions still need to communicate with the top officer for the purpose of coordination on compatibility between tasks iA and iB. Thus, there is a probability of $1-\lambda^{4 k}$ that the coordination on compatibility will fail: in such a case, the payoff will be 0 and we will be back to the situation of period 1. Therefore, we have,

$$
\pi_{\mathrm{m} 1}=\mathrm{p}\left\{\lambda^{4 \mathrm{k}}\left[(\mathrm{R}+1) / 2+\delta \pi_{\mathrm{k}}\right]+\left(1-\lambda^{4 \mathrm{k}}\right) \delta \pi_{\mathrm{m} 1}\right\}+(1-\mathrm{p})\left[\lambda^{4 \mathrm{k}} / 2+\delta \pi_{\mathrm{m} 1}\right],
$$

where $\pi_{\mathrm{k}}$ is the expected payoff from two regions when four messages need to be reported to the top officer for coordination on compatibility:

$$
\pi_{\mathrm{k}}=\lambda^{4 \mathrm{k}} \mathrm{R} /(1-\delta)+\left(1-\lambda^{4 \mathrm{k}}\right) \delta \pi_{\mathrm{k}},
$$

which gives:

$$
\pi_{\mathrm{k}}=\lambda^{4 \mathrm{k}} \mathrm{R} /\left\{(1-\delta)\left[1-\left(1-\lambda^{4 \mathrm{k}}\right) \delta\right]\right\}
$$

Therefore, we obtain:

$$
\pi_{\mathrm{m} 1}=\left\{\mathrm{p} \lambda^{4 \mathrm{k}}\left[(\mathrm{R}+1) / 2+\delta \pi_{\mathrm{k}}\right]+(1-\mathrm{p}) \lambda^{4 \mathrm{k}} / 2\right\} /\left\{1-\delta\left[\mathrm{p}\left(1-\lambda^{4 \mathrm{k}}\right)+1-\mathrm{p}\right]\right\} .
$$

Because of Assumption 1, pR > 1, then we have:

Lemma 5: Under the M-form experimentation in one unit is always dominated by immediate full change: $\pi_{\mathrm{m} 2}>\pi_{\mathrm{m} 1}$

Without the setup costs, there is no benefit from waiting as long as a blueprint is attractive (in expected terms) on a per-period basis. In this case, experimentation cannot be a good strategy.

Proposition 6: Comparing immediate full change under the M-form and the U-form:

(1) $\pi_{\mathrm{m} 2}=\pi_{\mathrm{u} 2}$ for $\lambda=1$. For $\lambda<1$, there exists $\mathrm{k}^{*}(\lambda, \mathrm{p})>0$ such that $\pi_{\mathrm{m} 2}>\pi_{\mathrm{u} 2}$ if and only if $\mathrm{k}<\mathrm{k}^{*}(\lambda$, $\mathrm{p})$.

In particular, for $\mathrm{p}=1, \mathrm{k}^{*}(\lambda, 1)=1 / 2$.

(2) There exists $\mathrm{k}^{*}(\lambda)$, where $0<\mathrm{k}^{*}(\lambda)<1 / 2$, such that: 
(i) for $\mathrm{k}<\mathrm{k}^{*}(\lambda), \pi_{\mathrm{m} 2}>\pi_{\mathrm{u} 2}$ for all $\mathrm{p}$;

(ii) for $\mathrm{k}^{*}(\lambda)<\mathrm{k}<1 / 2$, there exists $\mathrm{p}$ such that $\pi_{\mathrm{m} 2}>\pi_{\mathrm{u} 2}$ for $\mathrm{p}>\mathrm{p}$ and $\pi_{\mathrm{m} 2}<\pi_{\mathrm{u} 2}$ otherwise; and

(iii) for $\mathrm{k}>1 / 2, \pi_{\mathrm{m} 2}<\pi_{\mathrm{u} 2}$ for all $\mathrm{p}$.

The first part of Proposition 6 says that the tradeoff between the M-form and the U-form is that between the ability of coordination on attribute matching and that on compatibility. When coordinating compatibility is less demanding (i.e., $\mathrm{k}<\mathrm{k}^{*}$ ), then the $\mathrm{M}$-form has an advantage over the U-form. On the other hand, if coordinating compatibility is very demanding (i.e., $\mathrm{k}>\mathrm{k}^{*}$ ), coordination becomes less of a problem in the U-form than in the M-form; consequently, the U-form will dominate the M-form.

The second part of Proposition 6 says more. When attribute compatibility is not important compared to attribute matching, then the M-form is better than the U-form. When attribute compatibility is moderately important, then the M-form is better than the U-form if uncertainty of the blueprint is low, but the $\mathrm{U}$-form is better if the uncertainty is high. The reason is that $\pi_{\mathrm{m} 2}$ increases faster than $\pi_{\mathrm{u} 2}$ when $\mathrm{p}$ increases for moderate values of $\mathrm{k}$. When attribute compatibility is very important, than the U-form is always better.

\section{Reforms in Transition Economies}

Our first example on how organizational forms of governments affect reforms is agricultural reforms in China and former Soviet Union. The China reforms started in the late 1970s and early 1980s within the M-form planning system. The success of agriculture reform is closely related to the roles of regional governments in solving coordination problems in the reform. Associated with the deepening of the reform, planning is gradually abandoned. However, the inherited M-form structure of the government organization still play important roles in further reforms. In contrast, the Soviet Union started their agriculture reform in the 1980 s within the U-form planning system, which failed to coordinate reform related activities. This contributes to the ill fate of the agriculture reform. Moreover, problems inherited from U-form structure continuous to hamper transition after the collapse of the Soviet Union.

Agriculture reforms in both countries are centred at replacing collective farming by household 
farming. There are many "blueprints" of household farming. Control rights of land may be partly delegated to households for a short time period; or may be leased to households for a longer period of time. Alternatively, ownership of land may be transferred to households altogether. These reforms face blueprint uncertainty and implementation (attribute matching) problems. First, it is not clear ex ante how households would respond to incentives under different reform blueprints; ${ }^{13}$ Or how differfent blueprints would interatct with coordination problems.

Second, coordination problem arises in introducing household farming. Household farming allows households to choose new crops/ products for profits, say to change from grain to vegetables, fruits, aquatic products, diary products, etc. Producing and harvesting new products will involve interactions with other sectors. For example, when farmers change production from grain to fishery, compared with grain production, aquatic production/harvesting may interfere with water traffic and irrigations; moreover, transport and storage of aquatic products have substantial different requirements than those of grain. Only when related attribute matching problems are solved an agriculture reform can succeed.

Under the M-form planning structure, China regional governments, such as county governments have the responsibility of coordinating activities in agricultural production, transport, storage, and processing etc. It is in this institutional context, the agricultural household responsibility system was introduced/experimented through initiatives of some regional governments. Together with redistribution of control rights of lands, regional governments' coordination over economic activities across sectors and across households has played critical roles for reform to be successful.

Before the reform, the Chinese agriculture was over-concentrated on grain production. A major feature of the successful Chinese agricultural reform is the change of production (made by household farms with the coordination help of regional governments), from grain to other crops/products, such as aquatic products, animal husbandry, and fruits etc. Taking fishery sector as an example, at the national level the total output of aquatic products increased from 4.6 million tons in 1978 to 41.2 million tons in 1999; while total output of grain increased from 304.8 million tons in 1978 to 508.4 million tons in 1999. As a result the share of output value of fishery in agriculture gross output value increased from $1.4 \%$ in

\footnotetext{
${ }^{13}$ Households may doubt that the reform will continue. Such worries have good reasons; indeed a policy reversal did happen in the late 1960s in China and those hard working farmers who became richer suffered politically and economically.
} 
1978 to $10.3 \%$ in $1999 .^{14}$

When farmers choose to shift from grain production to fish farming, the physical and informational infrastructure requirements must be adapted. These involve substantial amount of coordination across sectors/industries, which household farms usually cannot do by themselves. Attribute matching problems may occur in the following dimensions:

(1) Conditions required for raising fish or fishing may be in conflict with requirements for water transport and irrigation of grain fields in terms of quality, quantity, location and timing of using water;

(2) Fish species may be region specific; moreover, selections of fish species and grain species are different in different areas;

(3) Transport and storage means required for harvesting fish differ from those for harvesting grain; and

(4) Disease control is different for fish and plants.

In the following, we use Xinhui county in Guangdong Province to illustrate how regional governments under a M-form structure solve these problems in the reform. All the material about this county are from Xinhui Xianzhi Editorial Committee $(1995,1997)$. Xinhui County government is responsible to coordinate economic activities in agriculture, industry, transportation, commerce, and $R \& D$, etc. within the county. Concerning agriculture, under the county government, there are 21 townships (or communes before 1984), which in turn coordinate 2800 villages (or production teams before 1984). Xinhui aquatic production increased very rapidly since the reform that the total aquatic output in 1985 increased by $230 \%$ than 1978 .

An important government agent in the aquatic sector in Xinhui is the County Aquatic Bureau, which has subordinate apparatus organizations to coordinate county-wide fresh water and ocean aquatic production, transport, processing, and supplies: a Fingerling, Fry and Fish Feed Company; a Fishing Admin Station; a Fishing Harbour Monitoring Station; an Aquatic New Technology Promotion Station; the Xinhui County Fishing Radio Station (is a specialized radio station for fishing production, transport, research and safety); the County Aquatic Supply and Marketing Company; and the County Aquatic Import and Export Company. In addition to this bureau, the county government also coordinates many agents responsible for other industries when the development of aquatic sector interact (or interfere) with other sectors, such as use of water; disease control; and infrastructure (fish boat harbours, radio, etc).

Under the M-form structure, Xinhui County government has has successfully made attribute matching

${ }^{14}$ Chinese statistics defines agriculture as consisted of farming, forestry, animal husbandry and fishery. 
in the growing fishery sector during the reform, which ensured a smooth transition to household farming along all four dimensions listed above:

First, a key factor in the growth of aquatic industry is the increase of the aquatic production area. Total aquatic production area can be increased by using rivers, ponds, and reservoirs. The coordination role of local government is important here. Attributes to be matched in order to increase the aquatic production area include timing, origination/destination/route, quality/quantity of water transmission to match demands in aquatic production, irrigation and transport. If too much water is diverted from a river into fishing ponds at a wrong time, the water level of the river may decrease too much, making transport difficult or leaving too little water for irrigation of rice fields. Water sharing for the purpose of irrigation and aquatic ponds has been coordinated by the county government. Part of the coordination is done by building new reservoirs to ensure regular water supply. It would be much more difficult to coordinate transport, irrigation, and aquatic activities if these were controlled by different specialized ministries separately.

Second, the selection of species best suitable for the county is also important. Some species fit better than others to a particular region's weather, water quality, water plants, plankton etc. The county government's Aquatic Bureau took the initiative in coordinating technological changes in aquatic production, such as helping select aquatic species best suitable for the county and giving technical support to aquatic farmers. For example, in 1979 the Aquatic Bureau helped to coordinate an enlargement of production of fingerling and fry. By 1985, the area of fish ponds for growing fingerling and fry increased by $65.8 \%$ compared with 1976 ; and the output of fingerling and fry increased by $130 \%$ over the same time period.

Third, the supply of fish feed and cold storage for harvested fish are other important factors that affect aquatic production. There are important attribute matching problems involved in fish feed supply (and similarly in cold storage services). When a new species of fish is introduced or whenever there is substantial change in weather conditions, requirements for fish feed (or for storage) must be adjusted accordingly, which in turn requires adjustments in raw materials used by fish feed plants. When markets were not yet well developed to take care of these problems, the county government played again an important coordination role. In 1979 the county government built a cold storage plant -- the Xinhui County Yamen Cold Storage Plant, which has provided ice, cold storage and processing (e.g. quick frozen) for aquatic industry in the county. In 1983 and 1984, jointly with some township governments the county government built two fish feed plants (Tangxia Fish Feed Plant and Hetang State-Township Joint 
Fish Feed Plant).

Fourth, disease control, in particular prevention of contagious fish diseases, is another critical factor and often requires an emergency response. Diseases may indeed spread via different waterways at a considerable speed. Disease control requires coordination between aquatic production, supply of drugs/disinfectants, transport, and irrigation, R\&D for the region and solutions specific to the local fish species. Controlling aquatic diseases is an emergency matter, requiring quick actions to specify drugs/disinfectants and the corresponding methods of using them, so time is of overriding importance. This is similar to dispatching an ambulance to meet particular requests in a medical emergency (Milgrom and Roberts, 1992). In this situation, markets may not be able to coordinate in time. The capacity of county government in coordinating all affected sectors is then critical for implementing disease control measures. In Xinhui, the Disease Prevention and Vaccination Department under the County Aquatic Bureau has played such a coordination role, taking into account various ecological problems. The Department provided fish immunization services and other medicines for fishes, for example, in 1985 it provided vaccination for 4.3 million Buffalo fish which increased substantially the survival rate of these fish.

As a result of the coordination role of local government, Xinhui aquatic production increased rapidly since the reform. Total aquatic production in Xinhui in 1985 increased by 2.3 times over that of 1978 . The success of Chinese local governments like Xinhui illustrates the strong capacity of the M-form structure in coordinating attribute matching. The local government has a good knowledge of local conditions and can respond efficiently given its authority in making attribute matching at the local level.

In a sharp contrast to the Chinese experience, in the Soviet Union, it appears that regional governments were not able to solve coordination problems arisen in their agricultural reforms. Associated with inherited problems of coordination in the transition total agricultural production in Russia declined by 29\% between 1990 and 1994 (Laird, 1997). Under the Soviet system, farming was subordinated to many different ministries. In the eighties, tasks related to agro-food industry are divided by 11 or even more ministries: The Ministry of Agriculture, Trade, Cereal and Grain Production, Fruit and Vegetable Farming, Machine Building for Animal Husbandry and Feed Production, Tractors and Farm Machinery, Land Reclamation and Water Resources, Meat and Dairy Industry, Food Industry, Rural Construction and Fertilizer Production (Wegren, 1998, p. 62). Regional authorities had no control over farming and played only a role of "expediters, throwing themselves in the search for batteries, belts and harvester blades, undoing complex knots in the supply system" (van Atta, 1993b). Tractors were 
provided centrally by the so-called MTS stations. The tasks of providing inputs to the farmers, of managing their operations, storage, processing, transport, road infrastructure were all allocated to separate agencies over which collective farms had no control. Warehouses and processing plants were more likely to be located hundreds of kms away from farms (van Atta, 1993a). Under this structure it is very hard to solve coordination problems. For example, within that structure, any change in grain production involves 5 ministries: Ministry of Agriculture, Trade, Cereal and Grain Production, Tractors and Farm Machinery, Food Industry, Rural Construction and Fertilizer. Any farm (private or collective) changes crops from grain to vegetable production, the farm has to deal with these ministries plus some other 2 ministries: Land Reclamation and Water Resources, Fruit and Vegetable Farming.

Before any reform measure was introduced, serious coordination problems created by this structure led to substantial waste at storage, transport and processing stages. Coordination failure was so important that at the end of the eighties, there was a consensus among experts of Soviet agriculture that the biggest problem in that sector was the at the distribution stage (Wädekin, 1992). In Russia, about a quarter of total grain products (average of 49 million tons of grain in 1986-1990) was wasted due to bad conditions of storage, rotting of bread. $30-40 \%$ of potatoes were lost to rot in storage places. Of the $40 \%$ loss in potatoes and vegetables, 1/3 was lost in bad transport and storage, $20 \%$ due to bad coordination (not enough transport capacity, not enough gas or oil, spare parts).

In the Soviet period, some reform attempts were introduced to change organizational forms partially to mitigate those problems in agriculture. In the 1980's, organizations called RAPO (raïonnoe agropromyshlennoe obyedinenie) were created to locally coordinate activities between the various ministries. However, this led to a conflict of authority between the functional ministries and the new regional coordination structure. The RAPO's did not have the power over resources controlled by the ministries 15 and they were generally ignored by the latter. Other attempts at reforms such as the introduction of an overarching ministry Gosagroprom, the introduction of agrofirms at a smaller scale and even the introduction of leasing contracts ( $a r e n d a$ ) failed similarly because of lack of control over the overall farming process (Butterfield, 1990).

In March 1989, the Central Committee of the Soviet Communist Party decided under Gorbachev's impulsion to launch a reform in agriculture whereby peasants could lease land with long term contracts up to 50 years. This may seem similar to the Chinese reform in the early 1980's but it left coordination problems

\footnotetext{
${ }^{15}$ Due to the U-form structure, production infrastructures remained geographically dispersed which
} 
to the farmers. Although leasing gave incentives to the peasants, farmers were dependent on the infrastructure and machinery, on the feed, fodder, seed, provided by agents under different ministries and technical support and mechanized assistance of the collective farm. Input supplies were not guaranteed.

After the collapse of the Soviet Union, although central planning was abandoned and privatisation was a policy problems inherited from the U-form structure continuous to cause great troubles for reforms aimed to establish household farms. One important heritage of the U-form structure is the lack of knowledge on coordinating household farming and the lack of facilities to support household farming. Under the U-form structure, the regional governments have no knowledge on how to help household farming even when they are willing to support private farming in principle.

Dairying industry is a good example. Dairying involves a complex and interdependent processes from forage productions to retailing. However, under the U-form planning structure, "those responsible for forage production have different reporting channels from those who are responsible for breeding. Those responsible for herd health - one element which contributes to the sanitary quality of milk - report to different people than those responsible for the maintenance of milking equipment - another element which contributes to sanitary quality. Furthermore, those responsible for individual segments of the dairy operation are each provided with separate production goals which are not compatible with obtaining the best results from the entire system. [...] As milk processing is someone else's responsibility, factors affecting milk quality become irrelevant for those involved in managing the dairy cows. There is little communication among those directly responsible for the various activities which make up dairying. Individual production workers receive top-down direction from those in charge of their segmented dairying activity." As a result, "given the compartmentalization of responsibilities" in the U-form structured planning system, there are no individuals who have a comprehensive and holistic understanding of dairying as a system. In addition to the lack of knowledge, it is also reported that "the large-scale, centralized animal facilities previously invested in will be impossible to divide and sharing arrangements will be complex and difficult to organize." (source....)

In general, serious coordination problems inherited from the Soviet system appeared to be a major factor which hampers Russia's privatisation in farming. Wehrheim et al. (2000) argue that underdeveloped institutions and infrastructure, such as a lack of a system of market information (where to buy and sell and at what price), are the main problem plaguing Russian agriculture. There is even

made regional coordination more difficult. 
evidence that the post-harvest waste has been increasing in the nineties. (Laird, 1997). Indeed, in many regions, the cost of shipping agricultural goods exceeds the producer prices (Liefert-Swinnen, 2002). Without proper solutions to the coordination problems, Russian private farmers have to work under very primitive conditions which discourage collective farm employees to become private farmers. S. Wegren, cites an article about how coordination problems hamper privatization in agriculture in Moscow oblast: once becoming private farmers "they immediately encountered massive problems - no machinery, nowhere to obtain gas, nowhere to sell produce, and so on. People saw this and did not want to follow their example." A survey by the World Bank in 1994 showed that 92\% of collectively-owned or stateowned farm employees did not want to become private farmers. The main reasons invoked were difficulties with purchase of farm inputs (60\% of respondents) and insufficient capital (74\%) (Brooks et al. 1994). A 1994 world bank sponsored survey in agriculture found that in two thirds of state farms, only less than 10 people (3 families) left (Wegren, 1998, p. 83). Moreover, for similar reasons land leasing also remained very limited and did not enjoy popularity among peasants (Wegren, p. 68).

Our next example concerns reform programs for expanding foreign trade and attracting foreign investments in China and in the FSU since the 1980s. When these two countries started reforms in this area, both governments issued decrees or ad hoc laws to support foreign investment. However, they both did not have constitutional protection of private property rights and they both did not have most of commercial codes. Therefore, it is conceivable that it is difficult to convince a large number of foreign investors that their investments in those countries are safe. In our terminology, such programs are associated with low p. Applying our model, the M-form would try small scale experiments whereas the U-form would either to experiment at full scale or choose not to experiment at all. Our predictions are consistent with what happened in China, where regional governments take substantial responsibilities to coordinate foreign trade and foreign investments within their regions, and FSU, where foreign trade and foreign investments are managed by specialized ministries (see Appendix).

In 1980, the Chinese government decided to try out different laws and governance in a few cities called Special Economic Zones (SEZs), which are coordinated by regional governments. The first group of small scall experiment for SEZ started in four cities in Guangdong province and Fujian province. In 1984, the experiment was expanded into another 14 cities in coastal provinces. As a result, till 1992 the SEZs 
are expanded into all the capital cities of inland provinces and include other 100 national and regional economic and technological development zones. Essentially SEZs have spread out all over the nation and they have great positive impacts in attracting FDI to China. Closely associated with this development, China becomes one of the major exporters in the world and the largest FDI reciepient country in the world (since 2004).

By contrast, consistent with our model's prediction, the FSU government always introduced reforms in foreign trade/investment at full scales nationwide. Concerning trade, in 1986 the Council of Ministers adopted the decree to change the structure of the foreign trade bureaucracy drasticly. This reallocated power from one ministry specialized in foreign trade to twenty-one ministries and state committees specialized in different industries. With respect to attracting foreign investments, in 1987, the Council of Ministers adopted a resolution -- a law on joint ventures. Implementation was carried out by specialized ministries.

The FSU foreign trade bureaucracy was created by the 1930 Decree Number 358. The council's State Foreign Economic Commission coordinated the activities of ministries and departments in foreign economic activities. They planned, regulated, monitored, and carried out all Soviet foreign economic activities. There are six central bodies under the Council of Ministries in foreign economic relations. The import and export of goods, services, and resources were managed by the State Planning Committee (Gosplan), the State Committee for Material and Technical Supply (Gossnab), and the State Committee for Science and Technology (GKNT). Gosplan formulated all import and export plans, coordinated the allocation of investment and other resources, and had final authority over all decisions concerning foreign trade, including trade levels and commodity composition. Gossnab coordinated the allocation of resources not handled by Gosplan and played a major role in selecting and allocating imports. GKNT negotiated technical cooperation agreements and monitored license and patent purchases and sales in order to introduce new technology into the Soviet economy.

The State Committee on Prices (Goskomtsen), the Ministry of Finance, and the State Bank (Gosbank) held jurisdiction over the financing of foreign trade. Goskomtsen established prices for all imports and 
some exports. The Ministry of Finance controlled the balance of payments and monitored the impact of foreign trade on the state budget. Finally, Gosbank set the exchange rate for the ruble (for value of the ruble--see Glossary) and managed the system of exchange within the Soviet Union. Gosbank supervised the Foreign Economic Activity Bank.

Moreover, some industrial ministries had their own Foreign Trade Organizations (FTOs). As of early 1987, for example, forty-eight FTOs were under the jurisdiction of the Ministry of Foreign Trade and nine under the GKES, whereas the Ministry of the Maritime Fleet, the Ministry of the Fishing Industry, and the Ministry of Trade, among others, had their own FTOs.

The lack of direct contact between Soviet enterprises and their foreign customers or suppliers delayed contract negotiations and the specification of technical details. The general director of the Ministry of Foreign Trade's All-Union Association for the Export and Import of Technical Equipment, Boris K. Pushkin reported that 'after an enterprise submitted a request for a foreign item, two to three years were required before it was included in the import plan and funds were allocated for its purchase. In the interim, the needs of the enterprise had often changed.'

In 1986 the Council of Ministers adopted the decree to change the structure of the foreign trade bureaucracy drasticly. Until 1987 the forty-eight FTOs subordinate to the Ministry of Foreign Trade administered more than 90 percent of Soviet foreign trade turnover. In 1987 the ministry lost control of 20 percent of Soviet foreign trade turnover. The government granted direct foreign trade rights to twentyone ministries and state committees, sixty-seven industrial enterprises, and eight interbranch scientific production complexes. Exporting enterprises gained the right to retain part of their hard-currency earnings. Each ministry or enterprise was to pay for its investment imports with its own hard currency, and the heads of ministries and enterprises became personally responsible for the efficient use of hardcurrency funds. These measures gave enterprises more influence in import decision making.

In 1987, the Council of Ministers adopted a resolution - a law on joint ventures. This legislation opened up enterprises inside the Soviet Union for the first time since the Bolshevik Revolution to foreign participation. But implementation was carried out by specialized ministries. Numerous obstacles arose in 
implementing the joint venture law. Complaints by Western partners dealt with uncertainties concerning Soviet trade regulations, problems with the supply of goods, difficulties finding qualified Soviet managers, problems in projecting production costs, and complications finding office space in Moscow. By August 1988, about 50 joint ventures were registered in the Soviet Union, and approximately 300 were under negotiation.

Similarly to agriculture, the differences in organizational form can explain differences in industrial reforms in China vs the Soviet Union as well as differences in privatization policies under transition. We lack the space to elaborate here on those examples.

\section{Other Applications}

In this section we apply our theory to other two areas: business firms and the organization of government.

\section{A. Business Firms}

We first revisit the three famous cases documented by Chandler $(1962,1977)$, all of them showing coordination failures between production and sales under a U-form when a corresponding firm introduced new products or adopted innovations. These coordination failures were a major impetus for the subsequent change of organizational form in these corporations from a U-form to an M-form. While the emerging M-form had many different varieties such as organization by geography, product, process, etc, they shared a common feature that units became self contained. Our theory can interpret the coordination failures under the U-form in a consistent way.

The first case is about du Pont. Before 1921, du Pont was organized as a U-form: under the headquarters there were functional units for production and sales respectively. After World War I du Pont expanded production from explosives to consumer products, such as paints (Chandler, 1962, pp. 7894). At that time, whenever a new chemical was developed which changed the attributes of explosives 
and paints, the production unit reported the attribute change to headquarters, which then sent commands to the sales unit. Then the sales unit learned the attributes of the new product and demonstrated them to customers. At the same time, the sales unit learned customers' preferences and translated them into a new set of attributes.

The expansion of product lines caused major coordination troubles in du Pont: there were too many mistakes and inertia in adjusting attributes. Du Pont started to have losses. The problem became most evident in 1919 when almost all the new final products, which required a great deal of coordination, had (sometimes heavy) losses. In contrast, in the same year nearly all the traditional du Pont products which did not require much coordination made profits (Chandler, 1962, p. 95). Moreover, while du Pont suffered heavy losses for some new products such as paints, most of its competitors who were specialized in paints did not have similar coordination problems and "were enjoying one of their most profitable years" (Chandler, 1962, p. 92). In the early 1920, a subcommittee under the Executive Committee at du Pont investigated and concluded that "the underlying problem was not one of selling, but organization." The subcommittee proposed to change du Pont into a multi-divisional organization. This conclusion was further confirmed when du Pont suffered even bigger losses in 1921 after every effort was made to improve informational channels while keeping the U-form under the President Irénée du Pont (Chandler, 1962, pp. 96-101). Later in 1921, failure to improve the organization's performance and the persistent losses convinced du Pont to reorganize the firm into an M-form. This solved the problem, and the organizational form has been kept stable since then (Chandler, 1996, pp. 104-113).

The second case is about Sears Roebuck \& Co. Before 1925, Sears, the largest mail-order firm in the U.S., was organized as a U-form. At the headquarters in Chicago, there were departments responsible for specialized functions nationwide, such as the Merchandise Department responsible for procurement, the Catalogue and Advertisement Departments responsible for sales, and the Operating Department responsible for distributing commodities from producers to customers (Chandler, 1962, pp. 226-232). The U-form structure worked well when the number of regions covered and the number of stores was not too large. 
When Sears expanded into many new territories, acquired a large number of new stores and factories, and involved in new businesses such as retailing, its coordination problems became severe. Many idiosyncratic regional issues were hard to manage through separate functional departments. To manage the vast multi-regional mail-order/retail network while keeping the U-form structure, Sears put territorial officers in charge of handling territorial-specific issues by giving them authority on their region's personnel issues (Chandler, 1962, pp. 253-256). However, without the authority to coordinate problems locally, this structure did not work. In fact, on many occasions, instead of reporting to functional departments, local shops often relied on territorial officers to solve their problems (Chandler, 1962, p. 259). In 1939 Sears started a reorganization based on a territorial principle and completed in 1948: under the headquarters there were multi-functional and autonomous territorial divisions, such as the Midwestern Zone, the North-Western Zone, the North Central Zone, etc (Chandler, pp. 268-282).

A similar story holds for the Ford Motors Company. Before World War II, with a U-form organization and a focus on the Model-T car, Ford was the largest car producer in the U.S. and its engineers were among the most innovative. Ford also developed inexpensive tractors and technically excellent airplanes. However, the separated production and sales structures led to a poor coordination between production and sales. Eventually, Ford failed in producing and selling tractors and air planes although technically it made them well (Chandler, 1962, p. 301, pp. 372-373).

Argyres (1995) tells the story of how IBM via its M-form corporation created organizational flexibility allowing its PC division to introduce "cc:Mail" (a communication software) and "Notes" (a multi-task software from Lotus Development Corporation) to face the tough competition in its market and could later achieve compliance with a very large-scale software called "the Systems Application Architecture" (SAA) aiming toward allowing different hardware and operating systems to exchange data.

\section{B. The Organization of Government and the Foundations of Federalism}

Two organizational forms of government have received much attention: the unitary state and the federal state. Our analysis starts to provide a theoretical foundation of both, especially federalism. France and Japan, among others, have a unitary state, and their governments are mainly organized along 
functional lines where specialized ministries concentrate most powers, leaving regional governments with relatively little authority ${ }^{16}$. The organizational form of the US government is a primary example of federalism. The fifty states have the constitutional rights and responsibilities for coordinating government activities inside their jurisdictions. This spawns an environment to try innovative policies for themselves.

It has been perceived a long time ago that the American federal system may facilitate experimenting innovative policies. It was argued in 1888 that "federalism enables people to try experiments which could not safely be tried in a large centralized country." (Bryce, 1901). A few decades later, the American Supreme Court Justice, Louis Brandeis, had a famous characterization of American federalism as the "laboratory of the states." By laboratories, he meant that the states could experiment with new solutions to social and economic problems. Those that worked could be applied nationally; those that failed could be discarded. He said in 1932, "it is one of the happy incidents of the federal system that a single courageous state may... serve as a laboratory; and try novel societal and economic experiments without risk to the rest of the country." (Osborne, 1988). Indeed, many changes of legal rules and government policies in America were initiated by some states, usually from richer or liberal states, such as Massachusetts, California, and New York. And these experiments were later imitated by other states.

Policy experimentation has drawn attention in political science and sociology and there is a large literature that looks at the timing of policy imitation across states in the U.S. That literature takes state level policy experimentation/imitation as given and focuses on the time path of new policies, such as policies on education, welfare, or civil rights etc., from their first tries in one state to general imitation or adoption by a large number of states. And the records date back to the late $18^{\text {th }}$ century. A non-controversial feature characterized in this literature is that similar to a technological innovation imitation process, a typical innovative policy adoption/diffusion process across states displays a S-shaped curve (for a survey, see Gray,

\footnotetext{
${ }^{16}$ It is interesting to note that France introduced some decentralization of power in 1981.
} 
1994; and Oates, 1999). ${ }^{17}$

Instead of focusing on diffusion, in this paper, we look at how federalism provides a flexible mechanism for state governments to coordinate policy experimentation; and for the federal government to take advantages of or to propagate successful experimentation results. In the following, we provide some examples that demonstrate how state experiments worked.

Our first example involves the origin of the New Deal policies - state policy experimentation. Facing the challenges and risks associated with the rapid industrialization of the American economy early this century, a few states initiated innovative policies within their jurisdictions, such as unemployment compensation schemes, massive public programs, and schemes related to deposit insurance and social security. Most of those programs were complementary to each other and state government coordination was critical to the implementation. Later, many of the successful ones were institutionalized at the federal level that speeded up the adoption of the policies. In fact, a large number of Roosevelt's New Deal policies were inspired or precisely copied from those successful state level experiments. Roosevelt acknowledged that, "practically all the things we've done [about the New Deal] in the federal government are like things Al Smith did as governor of New York." (Osborne, 1988).

Our next example involves state coordinated policy experiments to deal with challenges associated with the replacement of the traditional industries by high tech business in the last two decades. Since the late 1970 s there has been a trend in the U.S. on adopting new policies, such as reform of public education systems; creating public venture capital funds; setting up programs to match local academia and business to advance technological innovation etc. This trend began with 'experiments' in Massachusetts and California. With the help of the federal government's agents, successful policies were learned by the

\footnotetext{
${ }^{17}$ This literature has documented various innovation adoption paths of a large number of policy experiments across states. For example, the state-boards-of-education system was first tried in one state in 1784, and was adopted by 40 states in 1949; while the degree-requirement-for-elementary-school-teaching policy was first started in one state in 1930 and was adopted by 46 states in 1969 (Gray, 1973).
} 
Midwest. Then those spread out to the rest of the nation. For instance, heavily subsidized community college was rare before the mid-1970s. However, following the success models of Massachusetts and California it has become a standard public education institution in most states.

\section{Concluding Remarks}

Our theory on coordinating reforms in transition economies opens new perspectives on understanding how the differences in organizational forms in the EEFSU and China affected their transition paths. For the first time, we formally address the following questions: Why is China special in its use of experimental approaches? Why is the U-form not suitable for doing local experiments? The importance of understanding these questions lies in the fact that in the EEFSU, some experimental reforms that were introduced before their transition failed. On this basis, the regional experimental approach to reforming a planned economy has been discredited and abandoned during later transitions in these economies.

The difference between the M-form and the U-form is highly relevant in other aspects in centralized economies. Note that the consequences of a collapse of power at the center are much smaller in the M-form. For example, during the Cultural Revolution (1966-1976), the Chinese central government almost completely lost its ability to coordinate the economy, but the national economy did not collapse: National income dropped in two years $(-7.2 \%$ in 1967 and $-6.5 \%$ in 1968) and recovered quickly afterwards without much central government coordination.

In the context of transition and price liberalization where government coordination is replaced by market forces, the output response is likely to be different in both organizational forms. In a U-form economy with greater induced specialization and more widespread monopolies, price liberalization gives smaller outside options to firms in the domestic economy 
in terms of finding new suppliers and/or clients while making disruptions of existing output links more dramatic, which is much in line with the output fall models of Blanchard and Kremer (1997) and Roland and Verdier (1999). Blanchard and Kremer (1997) have emphasized the role of complexity in technological complementarities between firms in generating disruption. In our framework, complexity is not simply an exogenous technological variable. The choice of technology is affected by the organizational form. Even for a given technology, the M-form reduces the complexity of coordination because of the decentralization of decision-making to self-contained units. In contrast, by centralizing communication on attribute shocks, the U-form makes coordination more complex.

In the U-form economy, the higher degree of monopolization is likely to give single firms more holdup power over the government, possibly leading to more rent-seeking and soft budget constraints, whereas in the M-form economy competitive forces are likely to develop more easily from scratch, with single firms having less holdup power and less leverage via the government. The larger firms left by the U-form economy are likely to require more sophisticated management expertise to operate in the global economy compared to their counterparts in the M-form organization. A lack of fulfillment of requirements in terms of management expertise may lead to more disappointing results of privatization.

At a more general level, in this paper we introduced a method of modelling task coordination inside an organization as "attribute matching." Using this method, we developed a theoretical analysis of organizational forms in order to understand the performance of the Mform and $\mathrm{U}$-form organizations in coordinating changes. Our theory sheds new light on business organizations, transition economies, and the organization of government.

Our paper seems to be the first formal attempt to study how the M-form and U-form affect 
coordination problems within an organization. The paper mainly tries to provide a new conceptual framework while also deriving some predictions on the superiority of the M-form or the U-form, depending on the quality of communication within organizations, the uncertainty of innovations, and the costs of introducing innovations. This paves the way for empirical analysis in the comparison of organizations in the future. 


\section{Appendix. Mathematical Proofs}

Proof of Lemma 1: (1) Because

$$
\Pi_{\mathrm{u} 2}=2 \mathrm{p} \Pi\left[1-\left(1-\lambda^{2}\right)^{2} \delta\right] /\left\{1-\delta\left[\mathrm{p}\left(1-\lambda^{2}\right)^{2}+(1-\mathrm{p})\right]\right\},
$$

where both $\Pi=\lambda^{2} \mathrm{R} /\left\{2(1-\delta)\left[1-\left(1-\lambda^{2}\right) \delta\right]\right\}$ and $\left[1-\left(1-\lambda^{2}\right)^{2} \delta\right] /\left\{1-\delta\left[\mathrm{p}\left(1-\lambda^{2}\right)^{2}+(1-\mathrm{p})\right]\right\}$ increases in $\lambda$ (the latter because $[1-\mathrm{x} \delta] /\{1-\delta[\mathrm{px}+(1-\mathrm{p})]\}$ decreases in $\mathrm{x})$, then $\Pi_{\mathrm{u} 2}$ increases in $\lambda$.

(2) $\mathrm{c}_{\mathrm{u} 2}=\mathrm{C} /\left\{1-\left[\mathrm{p}\left(1-\lambda^{2}\right)^{2}+(1-\mathrm{p})\right] \delta\right\}$ decreases in $\lambda$.

$\mathrm{c}_{\mathrm{u} 2}<\mathrm{c}_{\mathrm{m} 2}$ if and only if

$1-\delta(1-p)<2\left[1-\delta\left(p\left(1-\lambda^{2}\right)^{2}+1-p\right)\right]$

if and only if

$2 \delta p\left(1-\lambda^{2}\right)^{2}+\delta(1-p)<1$,

which is valid for all $\lambda$ provided $\delta<1 /(1+p)$

Proof of Proposition 1: (1) By Lemma 1, at $\lambda=1, \Pi_{\mathrm{u} 2}={ }_{\Pi_{\mathrm{m} 2}}$; but $\mathrm{c}_{\mathrm{u} 2}=\mathrm{C} /(1-\delta(1-\mathrm{p}))<\mathrm{c}_{\mathrm{m} 2}=2 \mathrm{C} /(1-\delta(1-$

p)), then $U_{2}>M_{2}$. Also by Lemma $1, \Pi_{\mathrm{u} 2}$ increases in $\lambda$ and $c_{\mathrm{u} 2}$ decreases in $\lambda$, then $U_{2}=\Pi_{\mathrm{u} 2}-c_{\mathrm{u} 2}$

increases in $\lambda$. Because $M_{2}$ is independent of $\lambda$ and because $U_{2}$ goes to 0 as $\lambda$ decreases, then for $p$ and $C$ given there exists $\lambda>0$ such that $\mathrm{M}_{2}>\mathrm{U}_{2}$ if and only $\lambda<\lambda$.

(2) For any $\lambda<1, \mathrm{M}_{2}>\mathrm{U}_{2}$ at $\mathrm{C}=0$. When $\mathrm{c}_{\mathrm{u} 2}<\mathrm{c}_{\mathrm{m} 2}, \mathrm{c}_{\mathrm{m} 2}$ also increases faster than $\mathrm{c}_{\mathrm{u} 2}$ as $\mathrm{C}$ increases, therefore, for $\mathrm{p}$ and $\lambda$ given, such a $\mathrm{C}$ exists. $\left(\mathrm{U}_{2}\right.$ could be the same as $\mathrm{M}_{2}$ if both have the same value as the status quo at C.)

Proof of Lemma 2: (1) Note that $\mathrm{pR}(1+\delta) / 2+(1-\delta) / 2$ is a weighted sum of $\mathrm{pR}$ and 1 . Therefore, because $\mathrm{pR}>1$ by Assumption 1, then the sum is less than $\mathrm{pR}$, or $\Pi_{\mathrm{m} 1}<\Pi_{\mathrm{m} 2}$.

(2) Because $d \Pi_{\mathrm{m} 1} / \mathrm{dp}=[\mathrm{R}(1+\delta) / 2-\delta / 2] /[1-(1-\mathrm{p}) \delta]^{2}$ and $\mathrm{dc}_{\mathrm{m} 1} / \mathrm{dp}=-\delta^{2} \mathrm{C} /[1-(1-\mathrm{p}) \delta]^{2}$, we have:

$$
\mathrm{dM}_{1} / \mathrm{dp}=\left[\mathrm{R}(1+\delta) / 2-\delta / 2+\delta^{2} \mathrm{C}\right] /[1-(1-\mathrm{p}) \delta]^{2}>0 .
$$


Also because $\mathrm{d}_{\Pi_{\mathrm{m} 2}} / \mathrm{dp}=\mathrm{R} /[1-(1-\mathrm{p}) \delta]^{2}$ and $\mathrm{dc}_{\mathrm{m} 2} / \mathrm{dp}=-2 \mathrm{C} \delta /[1-(1-\mathrm{p}) \delta]^{2}$, then we have

$$
\mathrm{dM}_{2} / \mathrm{dp}=\{\mathrm{R}+2 \mathrm{C} \delta\} /[1-(1-\mathrm{p}) \delta]^{2}>0 .
$$

Therefore, by $\mathrm{R}(1+\delta) / 2<\mathrm{R}, \delta \mathrm{C}-1 / 2<2 \mathrm{C}$, we have $\mathrm{R}(1+\delta) / 2-\delta / 2+\delta^{2} \mathrm{C}<\mathrm{R}+2 \mathrm{C} \delta$, then, $\mathrm{dM}_{2} / \mathrm{dp}>$ $\mathrm{dM}_{1} / \mathrm{dp}>0$

\section{Proof of Proposition 2:}

(1) Because

$\mathrm{M}_{1}-\mathrm{M}_{2}=\{\mathrm{pR} / 2(1+\delta)+(1-\delta) / 2-\mathrm{pR}-(1-\delta) \mathrm{C}(1+\mathrm{p} \delta)+2 \mathrm{C}(1-\delta)\} /(1-\delta)[1-\delta(1-\mathrm{p})]$

$=[\mathrm{C}(1-\mathrm{p} \delta)-(\mathrm{pR}-1) / 2] /[1-\delta(1-\mathrm{p})]$,

then $M_{1}>M_{2}$ if and only if $p<\underline{p}$. Furthermore, $\underline{p}<1$ if and only if $R / 2(1-\delta)-C>1 / 2(1-\delta)$.

From $\mathrm{M}_{1}=1 /(1-\delta)$ we obtain:

$$
\mathrm{p}_{\mathrm{m} 1} *=(2 \mathrm{C}+1)(1-\delta) /\{\mathrm{R}(1+\delta)-2 \delta(\mathrm{C}(1-\delta)+1)\},
$$

and from $\mathrm{M}_{2}=1 /(1-\delta)$ we obtain:

$$
\mathrm{p}_{\mathrm{m} 2} *=(2 \mathrm{C}+1)(1-\delta) /(\mathrm{R}-\delta) .
$$

Then $\mathrm{p}_{\mathrm{m} 1} *<\mathrm{p}_{\mathrm{m} 2} *$ if and only if $\mathrm{R} / 2(1-\delta)-\mathrm{C}>1 / 2(1-\delta)$.

By Lemma 2, $\mathrm{p}_{\mathrm{m} 1} *<\mathrm{p}_{\mathrm{m} 2} *$ must imply that $\mathrm{p}_{\mathrm{m} 1} *<\mathrm{p}_{\mathrm{m} 2} *<\mathrm{p}$.

(2) follows directly from the expression for $\mathrm{M}_{1}-\mathrm{M}_{2}$.

Proof of Proposition 3: We note that

$$
\begin{gathered}
\Pi_{\mathrm{u} 2}=\mathrm{p}\left\{\lambda^{4}[\mathrm{R} /(1-\delta)]+2 \lambda^{2}\left(1-\lambda^{2}\right)[\mathrm{R} / 2(1-\delta)+\delta \Pi]\right\} /\left\{1-\delta\left[\mathrm{p}\left(1-\lambda^{2}\right)^{2}+(1-\mathrm{p})\right]\right\} \\
=\mathrm{p}\left\{\lambda^{4}[\mathrm{R}+\delta \mathrm{R} /(1-\delta)]+2 \lambda^{2}\left(1-\lambda^{2}\right)[\mathrm{R} / 2+\delta[\Pi+\mathrm{R} / 2(1-\delta)]\} /\left\{1-\delta\left[\mathrm{p}\left(1-\lambda^{2}\right)^{2}+(1-\mathrm{p})\right]\right\} .\right.
\end{gathered}
$$

Comparing $\Pi_{\mathrm{u} 2}$ with $\Pi_{\mathrm{u} 1}$, because $\mathrm{R}>(\mathrm{R}+1) / 2$ and $\mathrm{R} / 2(1-\delta) \geq \Pi$, then $\Pi_{\mathrm{u} 2}>\Pi_{\mathrm{u} 1}$. 
Proof of Proposition 4: (1) For $\lambda=1, \Pi_{\mathrm{u} 2}=\Pi_{\mathrm{m}_{2}}>\Pi_{\mathrm{m} 1}$ and $\mathrm{c}_{\mathrm{u} 2}<\mathrm{c}_{\mathrm{m} 1}<\mathrm{c}_{\mathrm{m} 2}$. Therefore, for $\lambda$ large enough, by continuity, $\mathrm{U}_{2}>\mathrm{M}_{2}$ and $\mathrm{U}_{2}>\mathrm{M}_{1}$.

(2) If $\lambda$ is small enough, $U_{2}$ will always be dominated by $M_{1}$ or $M_{2}$. The rest of the proposition follows directly from Proposition 2.

Proof of Lemma 3: $\Pi_{\mathrm{m} 11}>\Pi_{\mathrm{m} 2}$ if and only if

$$
\left\{\mathrm{R}\left(\mathrm{p}^{2}+\mathrm{p}(1-\mathrm{p})(1+\delta)\right)\right\} /(1-\delta)\left[1-\delta(1-\mathrm{p})^{2}\right]>\mathrm{pR} /\{(1-\delta)[1-(1-\mathrm{p}) \delta]\},
$$

if and only if

$$
[1-\delta(1-p)]\left(p^{2}+p(1-p)(1+\delta)\right)>p\left(1-\delta(1-p)^{2}\right)
$$

if and only if

$$
[1-\delta(1-p)](1+\delta(1-p))>1-\delta(1-p)^{2}
$$

if and only if

$$
1-\delta^{2}(1-p)^{2}>1-\delta(1-p)^{2}
$$

which is verified since $\delta<1$.

Similarly, $\mathrm{c}_{\mathrm{m} 11}<\mathrm{c}_{\mathrm{m} 2}$ if and only if

$$
2 C[1+\delta p(1-p)] /\left[1-\delta(1-p)^{2}\right]<2 C /[1-(1-p) \delta],
$$

if and only if

$$
(1-\delta(1-p))(1+\delta p(1-p))<1-\delta(1-p)^{2}
$$

if and only if

$$
\delta^{2} \mathrm{p}(1-\mathrm{p})^{2}>0
$$

which is verified.

Proof of Lemma 4: (1) $\Pi_{\mathrm{m} 11}>\Pi_{\mathrm{m} 1}$ if and only if

$$
\left\{\mathrm{R}\left(\mathrm{p}^{2}+\mathrm{p}(1-\mathrm{p})(1+\delta)\right)\right\} /(1-\delta)\left[1-\delta(1-\mathrm{p})^{2}\right]>[\mathrm{pR}(1+\delta)+(1-\delta)] / 2(1-\delta)[1-(1-\mathrm{p}) \delta],
$$


if and only if

$$
2\left\{\mathrm{R}\left(\mathrm{p}^{2}+\mathrm{p}(1-\mathrm{p})(1+\delta)\right)\right\}[1-(1-\mathrm{p}) \delta]>[\mathrm{pR}(1+\delta)+(1-\delta)]\left[1-\delta(1-\mathrm{p})^{2}\right]
$$

if and only if

$$
[2 \mathrm{pR}]\left[1-\delta^{2}(1-\mathrm{p})^{2}\right]>[\mathrm{pR}(1+\delta)+(1-\delta)]\left[1-\delta(1-\mathrm{p})^{2}\right]
$$

Because $\mathrm{pR}>1$ if and only if $2 \mathrm{pR}>\mathrm{pR}(1+\delta)+(1-\delta)$, furthermore, $1-\delta^{2}(1-\mathrm{p})^{2}>1-\delta(1-\mathrm{p})^{2}$, then the above inequality holds.

Similarly, $\mathrm{c}_{\mathrm{m} 11}>\mathrm{c}_{\mathrm{m} 1}$ if and only if

$$
2 \mathrm{C}[1+\delta \mathrm{p}(1-\mathrm{p})] /\left[1-\delta(1-\mathrm{p})^{2}\right]>\mathrm{C}(1+\mathrm{p} \delta) /[1-(1-\mathrm{p}) \delta]
$$

if and only if

$$
2-2 \delta(1-p)^{2}-2 \delta^{2} p(1-p)^{2}>1-\delta(1-p)^{2}+p \delta-\delta^{2} p(1-p)^{2},
$$

if and only if

$$
1>\delta\left[p+(1-p)^{2}+\delta p(1-p)^{2}\right]
$$

if and only if

$$
1-\delta>-\delta p(1-p)(1-\delta(1-p))
$$

which is always valid since $1>\delta(1-p)$.

(2) $M_{11}>M_{1}$ if and only if

$$
\begin{aligned}
& \left\{\mathrm{R}\left(\mathrm{p}^{2}+\mathrm{p}(1-\mathrm{p})(1+\delta)\right)-2 \mathrm{C}(1-\delta)(1+\delta \mathrm{p}(1-\mathrm{p}))\right\}[1-\delta(1-\mathrm{p})] \\
& >\{\mathrm{pR}(1+\delta) / 2+(1-\delta) / 2-\mathrm{C}(1-\delta)(1+\mathrm{p} \delta)\}\left[1-\delta(1-\mathrm{p})^{2}\right]
\end{aligned}
$$

if and only if

$$
\begin{aligned}
& \mathrm{R}\left(\mathrm{p}^{2}+\mathrm{p}(1-\mathrm{p})(1+\delta)-\mathrm{pR}(1+\delta) / 2-(1-\delta) / 2+\mathrm{C}(1-\delta)(1+\mathrm{p} \delta)-2 \mathrm{C}(1-\delta)(1+\delta \mathrm{p}(1-\mathrm{p}))\right. \\
& >\delta(1-\mathrm{p})\left\{\mathrm{R}\left(\mathrm{p}^{2}+\mathrm{p}(1-\mathrm{p})(1+\delta)\right)-2 \mathrm{C}(1-\delta)(1+\delta \mathrm{p}(1-\mathrm{p}))-(1-\mathrm{p})[\mathrm{pR}(1+\delta) / 2+(1-\delta) / 2-\mathrm{C}(1-\delta)(1+\mathrm{p} \delta)]\right\}
\end{aligned}
$$

if and only if

$$
\begin{aligned}
& (\mathrm{pR}-1)(1-\delta) / 2+\mathrm{pR} \delta(1-\mathrm{p})-\mathrm{C}(1-\delta)[1-\mathrm{p} \delta(2 \mathrm{p}-1)] \\
& >\delta(1-\mathrm{p})\{\mathrm{pR}[1+\delta(1-\mathrm{p})+\mathrm{p}] / 2-(1-\mathrm{p})(1-\delta) / 2-\mathrm{C}(1-\delta)(1+\mathrm{p}+\delta \mathrm{p}(1-\mathrm{p}))\}
\end{aligned}
$$

if and only if 


$$
\begin{aligned}
& (\mathrm{pR}-1)(1-\delta) / 2+\mathrm{pR} \delta(1-\mathrm{p})-\delta(1-\mathrm{p})[\mathrm{pR}(1+\delta(1-\mathrm{p})+\mathrm{p}) / 2-(1-\mathrm{p})(1-\delta) / 2] \\
& >\mathrm{C}(1-\delta)[1-\mathrm{p} \delta(2 \mathrm{p}-1)]-\delta(1-\mathrm{p}) \mathrm{C}(1-\delta)(1+\mathrm{p}+\delta \mathrm{p}(1-\mathrm{p}))
\end{aligned}
$$

if and only if

$$
\begin{aligned}
& (\mathrm{pR} / 2)[1-\delta+2 \delta(1-\mathrm{p})-\delta(1-\mathrm{p})(1+\mathrm{p}+\delta(1-\mathrm{p}))]-(1-\delta)\left(1-\delta(1-\mathrm{p})^{2}\right) / 2 \\
& >\mathrm{C}(1-\delta)[1-\mathrm{p} \delta(2 \mathrm{p}-1)-\delta(1-\mathrm{p})(1+\mathrm{p}+\delta \mathrm{p}(1-\mathrm{p}))]
\end{aligned}
$$

if and only if

$$
\begin{aligned}
& (\mathrm{pR} / 2)[1-\delta+\delta(1-\mathrm{p})(1-\mathrm{p}-\delta(1-\mathrm{p}))]-(1-\delta)\left(1-\delta(1-\mathrm{p})^{2}\right) / 2 \\
& >\mathrm{C}(1-\delta)[1-\delta+\delta \mathrm{p}(1-\mathrm{p})(1-\delta(1-\mathrm{p}))]
\end{aligned}
$$

if and only if

$$
\mathrm{pR}\left(1+\delta(1-\mathrm{p})^{2}\right)>2 \mathrm{C}[1-\delta+\delta \mathrm{p}(1-\mathrm{p})(1-\delta(1-\mathrm{p}))]+\left(1-\delta(1-\mathrm{p})^{2}\right)
$$

Proof of Proposition 5: (1) If $\mathrm{p}=1$, we know from proposition 2 that $\mathrm{M}_{2}$ dominates $\mathrm{M}_{1}$. It is easy to check that $\mathrm{M}_{11}$ and $\mathrm{M}_{2}$ are equivalent and equal to $\mathrm{R} /(1-\delta)-2 C$. If $\lambda=1$, then $\mathrm{U}_{2}=\mathrm{R} /(1-\delta)-\mathrm{C}$ which clearly dominates. If $\mathrm{p}<1$ but $\lambda=1, \mathrm{U}_{2}>\mathrm{M}_{1}$, because $\Pi_{\mathrm{u} 2}=\Pi_{\mathrm{m} 2}>\Pi_{\mathrm{m} 1}$ and $\mathrm{c}_{\mathrm{u} 2}<\mathrm{c}_{\mathrm{m} 1}$. At $\lambda=1, \mathrm{U}_{2}>\mathrm{M}_{11}$ if and only if

$$
[\mathrm{pR}-\mathrm{C}(1-\delta)] /(1-\delta)[1-\delta(1-\mathrm{p})]>\{\mathrm{pR}(1+\delta(1-\mathrm{p}))-2 \mathrm{C}(1-\delta)(1+\delta \mathrm{p}(1-\mathrm{p}))\} /(1-\delta)\left[1-\delta(1-\mathrm{p})^{2}\right]
$$

if and only if

$$
\left(1-\delta(1-p)^{2}\right)(p R-C(1-\delta))>[1-\delta(1-p)]\{p R(1+\delta(1-p))-2 C(1-\delta)(1+\delta p(1-p))\}
$$

if and only if

$$
\operatorname{pR}\left\{\left(1-\delta(1-p)^{2}\right)-\left[1-\delta^{2}(1-p)^{2}\right]\right\}>C(1-\delta)\left\{\left(1-\delta(1-p)^{2}\right)-2(1+\delta p(1-p))(1-\delta(1-p))\right\}
$$

if and only if

$$
-p R \delta(1-p)^{2}>-C\left[1-\delta(1-p)^{2}(1+2 \delta p)\right]
$$

if and only if

$$
\mathrm{pR} \delta(1-\mathrm{p})^{2}<\mathrm{C}\left[1-\delta(1-\mathrm{p})^{2}(1+2 \delta \mathrm{p})\right]
$$

We verify that $1>\delta(1-p)^{2}(1+2 \delta p)$ for all $p$ and $\delta<1$. Therefore, when $C>C^{2}=p R \delta(1-p)^{2} /[1-\delta(1-$ 
$\left.p)^{2}(1+2 \delta p)\right], U_{2}>M_{11}$ at $\lambda=1$.

(2) If $\lambda$ is low enough, then $U_{2}$ is dominated. By Lemma $4, M_{1}$ dominates if and only if $C>C^{1}$.

(3) By Lemma 3, $M_{11}$ always dominates $M_{2}$. By Proposition 2, $M_{2}>M_{1}$ for $p>p$. Therefore, $M_{11}>M_{1}$ for $p>p$. Again if $\lambda$ is low enough, $U_{2}$ is dominated. The rest follows from Lemma 4. Because $M_{11}, M_{1}$ and $\mathrm{M}_{2}$ are independent of $\lambda$, for such $\mathrm{p}, \mathrm{M}_{11}>\mathrm{U}_{2}$ for low enough values of $\lambda$. Similarly, because both $M_{11}$ and $M_{1}$ are independent of $\lambda$ and, by Lemma $4, M_{11}$ dominates $M_{1}$ for $C<C^{1}$. For any such $C, U_{2}$ goes to 0 when $\lambda$ becomes small, then $M_{11}$ also dominates $U_{2}$ for $\lambda$ low enough. From the proof of (1), we know that $\mathrm{M}_{11}>\mathrm{U}_{2}$ if $\lambda=1$ and $\mathrm{C}<\mathrm{C}^{2}$

\section{Proof of Lemma 5: Because}

$$
\begin{gathered}
\left(\Pi_{\mathrm{m} 2}-\Pi_{\mathrm{m} 1}\right)\left\{1-\delta\left[\mathrm{p}\left(1-\lambda^{4 \mathrm{k}}\right)+1-\mathrm{p}\right]\right\}=\mathrm{p}\left\{\lambda^{4 \mathrm{k}}\left(\mathrm{R}+\delta \mathrm{R} /(1-\delta)-(\mathrm{R}+1) / 2-\delta \Pi_{\mathrm{k}}\right\}-(1-\mathrm{p}) \lambda^{4 \mathrm{k}} / 2\right. \\
=\mathrm{p} \lambda^{4 \mathrm{k}}\left[\mathrm{R} / 2+\delta \mathrm{R} /(1-\delta)-\delta \Pi_{\mathrm{k}}\right]+(-\mathrm{p}-1+\mathrm{p}) \lambda^{4 \mathrm{k}} / 2 \\
=\mathrm{p} \lambda^{4 \mathrm{k}} \delta\left[\mathrm{R} /(1-\delta)-\Pi_{\mathrm{k}}\right]+\lambda^{4 \mathrm{k}}(\mathrm{pR}-1) / 2 .
\end{gathered}
$$

Since $\Pi_{k}=R /(1-\delta)$ for $k=0$ and decreases in $k, \Pi_{k} \leq R /(1-\delta)$. Therefore, as $1-\delta\left[p\left(1-\lambda^{4 k}\right)+1-p\right]>0$ and $p R$ $>1, \Pi_{\mathrm{m} 2}>\Pi_{\mathrm{m} 1}$

Proof of Proposition 6: (1) Given any $\lambda<1$ and $\mathrm{p}, \Pi_{\mathrm{u} 2}$ is independent of $\mathrm{k}$ and $\Pi_{\mathrm{m} 2}$ is a decreasing function of $\mathrm{k}$. For $\lambda<1, \Pi_{\mathrm{m} 2}>\Pi_{\mathrm{u} 2}$ at $\mathrm{k}=0$, therefore, such $\mathrm{k}^{*}$ exists. In particular, at $\mathrm{p}=1$,

$$
\Pi_{\mathrm{m} 2} / \Pi_{\mathrm{u} 2}=\lambda^{4 \mathrm{k}}\left[\left(1-\left(1-\lambda^{2}\right) \delta\right] / \lambda^{2}\left[1-\left(1-\lambda^{4 \mathrm{k}}\right)\right]\right.
$$

Then $\mathrm{k}^{*}(\lambda, 1)=1 / 2$.

(2) We have:

$$
\Pi_{\mathrm{m} 2} / \Pi_{\mathrm{u} 2}=\lambda^{4 \mathrm{k}-2}\left(1-\left(1-\lambda^{2}\right) \delta\right)\left\{1-\delta\left[\mathrm{p}\left(1-\lambda^{2}\right)^{2}+1-\mathrm{p}\right]\right\} /\left[1-\delta\left(\mathrm{p}\left(1-\lambda^{4 \mathrm{k}}\right)+1-\mathrm{p}\right)\right]\left[1-\left(1-\lambda^{2}\right)^{2} \delta\right],
$$

from which we derive:

$$
\mathrm{d}\left(\Pi_{\mathrm{m} 2} / \Pi_{\mathrm{u} 2}\right) / \mathrm{dp}>0
$$

if and only if 


$$
-\left[1-\delta\left(p\left(1-\lambda^{4 k}\right)+1-p\right)\right]\left[\left(1-\lambda^{2}\right)^{2}-1\right]+\left[1-\delta\left(p\left(1-\lambda^{2}\right)^{2}+1-p\right)\right]\left[\left(1-\lambda^{4 k}\right)-1\right]>0,
$$

if and only if

$$
(1-\delta)\left[\left(1-\lambda^{4 k}\right)-\left(1-\lambda^{2}\right)^{2}\right]>0 .
$$

Let $\mathrm{k}^{*}(\lambda)$ be such that $1-\lambda^{4 \mathrm{k}^{*}(\lambda)}=\left(1-\lambda^{2}\right)^{2}$, then $0<\mathrm{k}^{*}(\lambda)<1 / 2$ and $\mathrm{d}\left(\Pi_{\mathrm{m} 2} / \Pi_{\mathrm{u} 2}\right) / \mathrm{dp}>0$ if and only if $\mathrm{k}>$ $\mathrm{k}^{*}(\lambda)$

By part (1), at $\mathrm{p}=1, \Pi_{\mathrm{m} 2}>\Pi_{\mathrm{u} 2}$ if and only if $\mathrm{k}<1 / 2$. Then, for $\mathrm{k}>1 / 2, \Pi_{\mathrm{m} 2}<\Pi_{\mathrm{u} 2}$ at $\mathrm{p}=1$, then $\mathrm{d}\left(\Pi_{\mathrm{m} 2} / \Pi_{\mathrm{u} 2}\right) / \mathrm{dp}>0$ implies that $\Pi_{\mathrm{m} 2}<\Pi_{\mathrm{u} 2}$ for all $\mathrm{p}$. For $\mathrm{k}^{*}(\lambda)<\mathrm{k}<1 / 2, \Pi_{\mathrm{m} 2}>\Pi_{\mathrm{u} 2}$ at $\mathrm{p}=1$, then $\mathrm{d}\left(\Pi_{\mathrm{m} 2} / \Pi_{\mathrm{u} 2}\right) / \mathrm{dp}>0$ implies that there exists $\mathrm{p}$ such that $\Pi_{\mathrm{m} 2}>\Pi_{\mathrm{u} 2}$ for $\mathrm{p}>\mathrm{p}^{*}$ and $\Pi_{\mathrm{m} 2}<\Pi_{\mathrm{u} 2}$ for $\mathrm{p}<\mathrm{p}^{*}$. For $\mathrm{k}$ $<\mathrm{k}^{*}(\lambda), \Pi_{\mathrm{m} 2}>\Pi_{\mathrm{u} 2}$ at $\mathrm{p}=1$, then $\mathrm{d}\left(\Pi_{\mathrm{m} 2} / \Pi_{\mathrm{u} 2}\right) / \mathrm{dp}<0$ implies that $\Pi_{\mathrm{m} 2}>\Pi_{\mathrm{u} 2}$ for all $\mathrm{p}$. 


\section{References}

Aghion, Philippe and Jean Tirole. "Some Implications of Growth for Organizational Form and Ownership Structure." European Economic Review, April 1995, 39(3-4), pp. 440-55.

Aoki, Masahiko. "Horizontal vs. Vertical Information Structure of the Firm." American Economic Review. December 1986, pp. 971-83.

Argyres, Nicholas S. "Technology Strategy, Governance Structure and Inter-divisional Coordination." Journal of Economic Behavior and Organization, 1995, 28, pp. 337-58.

Athey, Susan, and Armin Schmutzler. "Product and Process Flexibility in an Innovative Environment." RAND Journal of Economics, 1995, 26(4), pp. 557-74.

Becker, Gary, and Kevin Murphy. "The Division of Labor, Coordination Costs, and Knowledge." Quarterly Journal of Economics, November 1992.

Blanchard, Olivier, and Michael Kremer. "Disorganization." Quarterly Journal of Economics, November 1997, 112(4), pp. 1091-1126.

Bolton, Patrick, and Mathias Dewatripont. "Firms as Communication Network." Quarterly Journal of Economics, 1994, pp.

Bolton, Patrick, and Joseph Farrell. "Decentralization, Duplication and Delay." Journal of Political Economy, August 1990, 98(4), pp.

Bryce, James (1901), The American Commonwealth, London: Macmillan (first published 1888).

Butterfield, John. "Devolution in Decision-Making and Organizational Change in Soviet Agriculture," in W. Moskoff (ed.), Perestroika in the Countryside. Sharpe, pp. 19-46, 1990.

Byrd, William A. and Gene Tidrick. "The Chongqing Clock and Watch Company," in William Byrd (ed.), Chinese Industrial Firms under Reform, Oxford: Oxford University Press, 1992.

Chandler, Alfred Jr. Strategy and Structure. New York: Doubleday \& Company, Inc., 1962.

Chandler, Alfred Jr. The Visible Hand: The Managerial Revolution in American Business. Cambridge: Belknap Press of Harvard University Press, 1977.

Cremer, Jacques. "A Partial Theory of the Optimal Organization of Bureaucracy." Bell Journal of Economics, 1980, 11, pp. 683-693.

Dewatripont, Mathias, and Gérard Roland. "The Design of Reform Packages under Uncertainty." American Economic Review, December 1995, 85(5), pp. 1207-1223.

Dewatripont, Mathias, and Gérard Roland. "Transition as a Process of Large-Scale Institutional Change", in Kreps, David, and Kenneth Wallis (ed.), Advances in Economic Theory, Cambridge University Press, vol. II, pp. 240-278. 
Ericson, Richard E. "The Classical Soviet-Type Economy: Nature of the System and Implications for Reform." Journal of Economic Perspectives, 1991, 5(4), pp. 11-27.

Galbraith, Jay. Designing Complex Organizations, Addison-Wesley, 1973.

Granick, David. Chinese State Enterprises: A Regional Property Rights Analysis. Chicago: Chicago University Press, 1990.

Gray, Virginia, (1973), "Innovation in the States: A Diffusion Study,” American Political Review, 67: 1174-85.

Gray, Virginia, (1994), "Competition, Emulation, and Policy Innovation," in New Perspectives on

American Politics, ed, Lawrence C. Dodd and Calvin Jillson, Washington DC: CQ Press.

Gregory, Paul, and Robert Stuart. Comparative Economic Systems, third edition. Boston: Houghton Mifflin, 1989.

Hayek, Friedrich. "The Use of Knowledge in Society." American Economic Review, 1945, 35, pp. 519-30.

Hewett, Edward A. Reforming the Soviet Economy, Washington D.C.: the Brookings Institution, 1988.

IMF, World Bank, OECD and EBRD. A Study of the Soviet Economy, Vol. II\&III, Paris: OECD, 1991.

March, James, and Herbert Simon. Organizations, 2nd edition, 1993.

Marschak, Jacob, and Roy Radner. Economic Theory of Teams. Yale University Press, 1972.

Maskin, Eric, Yingyi Qian, and Chenggang Xu. "Incentives, Information, and Organizational Form." Review of Economic Studies, forthcoming, 1999.

McMillan, John, and Barry Naughton. "How to Reform a Planned Economy: Lessons from China." Oxford Review of Economic Policy, Spring 1992, 8, pp.

Milgrom, Paul, and John Roberts. "The Economics of Modern Manufacturing: Products, Technology and Organization." American Economic Review, June 1990, 80(3), pp. 511-28.

Milgrom, Paul, and John Roberts. Economics, Organization, and Management. Prentice Hall, 1992.

Nove, Alec. The Soviet Economic System, second edition. Boston: Allen \& Unwin. 1980.

Oates, Wallace (1999), “An Essay on Fiscal Federalism,” Journal of Economic Literature, 37(3): 1120-49.

Osborne, David. Laboratories of Democracy. Boston: Harvard Business School Press, 1988.

Qian, Yingyi, and Chenggang Xu. "Why China's Economic Reform Differ: The M-form Hierarchy and Entry/Expansion of the Non-state Sector." Economics of Transition, June 1993, 1(2), pp. 135170. 
Roland, Gérard, and Thierry Verdier. "Transition and the Output Fall." Economics of Transition, February 1999, 7(1), pp. 1-28.

Sachs, Jeffrey, and Wing T. Woo. "Understanding China's Economic Performance," mimeo, Harvard University, 1997.

Van Atta, D. "Russian Agriculture between Plan and Market," in van Atta (ed.), The "Farmer Threat," Westview Press, Boulder Colorado, 1993a, pp. 9-24.

Van Atta, D. "The Return of Individual Farming in Russia," in van Atta (ed.), The "Farmer Threat," Westview Press, Boulder Colorado, 1993b, pp. 71-95.

Weitzman, Martin. "Price vs. Quantities." Review of Economic Studies, 1974, 41, pp.477-91.

Williamson, Oliver. Markets and Hierarchies, New York: Free Press, 1975.

Williamson, Oliver. The Economic Institutions of Capitalism, New York: Free Press, 1985. 